\title{
Global chemical weather forecasts for field campaign planning: predictions and observations of large-scale features during MINOS, CONTRACE, and INDOEX
}

\author{
M. G. Lawrence ${ }^{1}$, P. J. Rasch ${ }^{2}$, R. von Kuhlmann ${ }^{1}$, J. Williams ${ }^{1}$, H. Fischer ${ }^{1}$, M. de Reus ${ }^{1}$, J. Lelieveld ${ }^{1}$, P. J. Crutzen ${ }^{1}$,

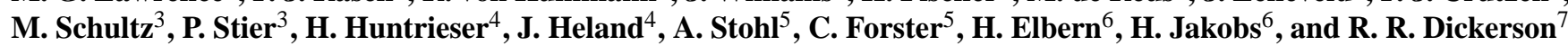 \\ ${ }^{1}$ Max-Planck-Institut für Chemie, Postfach 3060, 55020 Mainz, Germany \\ ${ }^{2}$ National Center for Atmospheric Research, Boulder, Colorado, USA \\ ${ }^{3}$ Max-Planck-Institut für Meteorologie, Hamburg, Germany \\ ${ }^{4}$ Institut für Physik der Atmosphäre, Deutsches Zentrum für Luft- und Raumfahrt, Oberpfaffenhofen, Germany \\ ${ }^{5}$ Technische Universität München, München, Germany \\ ${ }^{6}$ Institut für Geophysik und Meteorologie, Universität zu Köln, Köln, Germany \\ ${ }^{7}$ Department of Meteorology, University of Maryland, College Park, Maryland, USA
}

Received: 26 July 2002 - Published in Atmos. Chem. Phys. Discuss.: 15 October 2002

Revised: 17 January 2003 - Accepted: 29 January 2003 - Published: 26 February 2003

\begin{abstract}
The first global tropospheric forecasts of $\mathrm{O}_{3}$ and its precursors have been used in the daily flight planning of field measurement campaigns. The 3-D chemistry-transport model MATCH-MPIC is driven by meteorological data from a weather center (NCEP) to produce daily 3-day forecasts of the global distributions of $\mathrm{O}_{3}$ and related gases, as well as regional $\mathrm{CO}$ tracers. This paper describes the forecast system and its use in three field campaigns, MINOS, CONTRACE and INDOEX. An overview is given of the forecasts by MATCH-MPIC and by three other chemical weather forecast models (EURAD, ECHAM, and FLEXPART), focusing on $\mathrm{O}_{3}$ and $\mathrm{CO}$. Total $\mathrm{CO}$ and regional $\mathrm{CO}$ tracers were found to be the most valuable gases for flight planning, due to their relatively well-defined anthropogenic source regions and lifetimes of one to a few months. $\mathrm{CO}$ was in good agreement with the observations on nearly all the flights (generally $r>0.7$, and the relative RMS differences for the deviations from the means was less than $20 \%$ ). In every case in which the chemical weather forecasts were primarily responsible for the flight plans, the targeted features were observed. Three forecasted phenomena are discussed in detail: outflow from Asia observed in the Mediterranean upper troposphere during MINOS, outflow from North America observed in the middle troposphere over northern Eu-
\end{abstract}

Correspondence to: M. G. Lawrence

(lawrence@mpch-mainz.mpg.de) rope during CONTRACE, and the location of the "chemical ITCZ" over the Indian Ocean during INDOEX. In particular it is shown that although intercontinental pollution plumes such as those observed during MINOS and CONTRACE occur repeatedly during the months around the campaigns, their frequency is sufficiently low $(\sim 10-30 \%$ of the time) that global chemical weather forecasts are important for enabling them to be observed during limited-duration field campaigns. The MATCH-MPIC chemical weather forecasts, including an interface for making customized figures from the output, are available for community use via http: //www.mpch-mainz.mpg.de/ lawrence/forecasts.html.

\section{Introduction}

Field campaigns are an essential component in the study of physical and chemical processes controlling trace gas and aerosol concentrations in the atmosphere. Since the variability in meteorological fields and in production and loss processes results in variations in the distributions of gases and aerosols, careful planning is required in order to maximize the use of available resources to attain campaign objectives. While numerical weather prediction models and trajectory models have a long history of being used in campaign flight planning, chemistry-transport models (CTMs) have only re- 
Table 1. CO Tracers and bounding regions

\begin{tabular}{|c|c|c|c|}
\hline Tracer Name & Region & Latitude & Longitude \\
\hline CO_WEU & Western Europe & $35^{\circ} \mathrm{N}-70^{\circ} \mathrm{N}$ & $10^{\circ} \mathrm{W}-15^{\circ} \mathrm{E}$ \\
\hline CO_EEU & Eastern Europe ${ }^{1}$ & $35^{\circ} \mathrm{N}-75^{\circ} \mathrm{N}$ & $15^{\circ} \mathrm{E}-40^{\circ} \mathrm{E}$ \\
\hline CO_AFR & Africa & $35^{\circ} \mathrm{S}-35^{\circ} \mathrm{N}$ & $20^{\circ} \mathrm{W}-60^{\circ} \mathrm{E}$ \\
\hline \multirow[t]{2}{*}{ CO_NAS } & Northern Asia $^{2}$ & $30^{\circ} \mathrm{N}-70^{\circ} \mathrm{N}$ & $60^{\circ} \mathrm{E}-90^{\circ} \mathrm{E}$ \\
\hline &. & $20^{\circ} \mathrm{N}-70^{\circ} \mathrm{N}$ & $90^{\circ} \mathrm{E}-150^{\circ} \mathrm{E}$ \\
\hline \multirow[t]{2}{*}{ CO_SAS } & Southern $\mathrm{Asia}^{2}$ & $0^{\circ} \mathrm{N}-30^{\circ} \mathrm{N}$ & $60^{\circ} \mathrm{E}-90^{\circ} \mathrm{E}$ \\
\hline & .. & $10^{\circ} \mathrm{S}-20^{\circ} \mathrm{N}$ & $90^{\circ} \mathrm{E}-150^{\circ} \mathrm{E}$ \\
\hline CO_AUS & Australia & $45^{\circ} \mathrm{S}-15^{\circ} \mathrm{S}$ & $110^{\circ} \mathrm{E}-160^{\circ} \mathrm{E}$ \\
\hline CO_NAM & North America & $15^{\circ} \mathrm{N}-75^{\circ} \mathrm{N}$ & $135^{\circ} \mathrm{W}-45^{\circ} \mathrm{W}$ \\
\hline CO_SAM & South America & $55^{\circ} \mathrm{S}-10^{\circ} \mathrm{N}$ & $80^{\circ} \mathrm{W}-35^{\circ} \mathrm{W}$ \\
\hline
\end{tabular}

1 Also includes emissions from some Middle East countries

2 The northern and southern Asian CO tracer regions consist of two rectangles each, so that China is placed in the northern Asian region and India is in the southern Asian region.

cently begun to be employed for this purpose. CTMs provide direct information on the expected state of atmospheric trace constituents on timescales of hours to days - the "chemical weather" - which depends on the integrated effects of meteorology, sources, photochemical reactions, aerosol nucleation and growth, and loss processes which an airmass undergoes prior to when it is sampled. In combination with information on the regional "chemical climate" - seasonal statistics of trace gas and aerosol distributions based on multi-year historical CTM or coupled chemistry-climate model runs - forecasts of the chemical weather will likely become the primary tool for the daily planning of future atmospheric chemistry field campaigns.

Chemical weather forecasting for the stratosphere was first done for the ASHOE and SESAME campaigns (1994-95), during which Lee et al. (1997) used two global stratospheric CTMs (TOMCAT and SLIMCAT) to compute the anticipated levels of $\mathrm{O}_{3}$ and other constituents of the arctic polar vortex starting two weeks prior to each deployment. The first regional tropospheric chemistry forecasts were provided for the 1997 POLINAT campaign using the NILU chemistrytransport model (Flatoy et al., 2000).

Global tropospheric $\mathrm{O}_{3}$-chemistry forecasts were computed for the first time during the 1999 Indian Ocean Experiment (INDOEX) with a prototype of the MATCH-MPIC system described here. Following that, global CO-tracer forecasts were computed during TRACE-P (April 2000) by both the ECHAM GCM (described in the Appendix) and the Harvard GEOS-CHEM CTM (http://www-as.harvard.edu/ chemistry/trop/geos/geos_traps.html), and chemical weather forecasts were also provided by a variety of continental-scale regional models. An updated MATCH-MPIC forecast system was employed during MINOS (the Mediterranean In- tensive Oxidants Study, July-August 2001), along with the ECHAM CO-tracer forecasts, and again during CONTRACE (Convective Transport of Trace Gases into the Upper Troposphere over Europe, November 2001), in addition to global CO-tracer forecasts computed using the FLEXPART model, and regional chemical weather forecasts using the EURAD model (both described in the Appendix). A different version of MATCH is also being used to compute global aerosol forecasts, which have been employed primarily during INDOEX and ACE-Asia; the aerosol forecasts profit from the assimilation of satellite measurements of aerosol optical depth, and are described elsewhere (Collins et al., 2001; Rasch et al., 2001).

The use of chemical weather forecasts in field campaigns is expanding rapidly. For instance, new forecast systems with regional CO tracers using the GEOS-CHEM (Harvard) model and with gas phase $\mathrm{O}_{3}$-related chemistry using MOZART (NCAR/Hamburg/GFDL) and CHASER (University of Tokyo) were set up for use during ITCT $2 \mathrm{k} 2$ and PEACE-B (April-May 2002, see http://www.al.noaa.gov/ WWWHD/pubdocs/ITCT/2k2 and http://www.eorc.nasda. go.jp/AtmChem/GLACE/PEACE/htdocs/pcb.html). These campaigns also employed the global MATCH-MPIC and FLEXPART forecasts, the global aerosol forecasts by MATCH (NCAR), and various regional chemical weather forecast products. Recent developments in stratospheric chemical weather forecasting include the assimilation of global $\mathrm{O}_{3}$ columns from satellite observations (Eskes et al., 2002). Several regional chemical weather forecast systems have been set up at national weather centers. Extreme advances in resolution may also soon be possible; recently, forecasts with a cloud resolving model $(\Delta X \approx 1 \mathrm{~km})$ have been used in a field campaign focused on convective activ- 
ity (Benoit et al., 2002). International activities are being planned for the near future to develop elaborate global and nested-regional chemical weather forecast systems.

In light of this extensive effort, it is important to assess the quality and value of chemical weather forecasts in past field campaigns, and to consider where the most effort should be focused in the near future. Here we discuss the use of the MATCH-MPIC chemical weather forecast system during MINOS, CONTRACE and INDOEX. Following a description of the model and the forecast system setup in the next section, we give a brief overview of the chemical weather forecasts and their use during the three campaigns, focusing on $\mathrm{O}_{3}$ and $\mathrm{CO}$. The model results are compared with the observations, documenting for the first time that a tropospheric CTM such as MATCH-MPIC is capable of successfully forecasting several different types of pollution outflow. We then examine three forecasted phenomena in detail: the Asian monsoon plume over the Mediterranean (MINOS), the North American outflow observed over Europe (CONTRACE), and the location of the "chemical ITCZ" (intertropical convergence zone) over the Indian Ocean (INDOEX). We conclude with our perspectives on future developments in chemical weather forecasting.

\section{Forecast model system setup}

The chemical weather forecast system uses the Model of Atmospheric Transport and Chemistry, Max-Planck-Institute for Chemistry version 3.0 (hereafter MATCH-MPIC), described and evaluated in Rasch et al. (1997), Mahowald et al. (1997a,b), Lawrence et al. (1999), von Kuhlmann (2001) and von Kuhlmann et al. (2003). A description of the model is given in the Appendix. In addition to the extensive nonmethane hydrocarbon (NMHC) oxidation mechanism described in von Kuhlmann (2001) and von Kuhlmann et al. (2003), the forecast runs include regional CO tracers. These have the same emissions as the normal $\mathrm{CO}$ over a chosen region (only industrial and biomass burning emissions are included, not secondary production from VOC oxidation or oceanic emissions), and are subjected to the model transport algorithms and the same losses as normal $\mathrm{CO}$ (note that dry deposition of the $\mathrm{CO}$ tracers was not included during MINOS and CONTRACE, but has since been incorporated). A list of the $\mathrm{CO}$ tracers and their bounding regions is given in Table 1 .

The basic procedure for producing the daily forecasts is outlined in Fig. 1. Each day's run is fully automated and consists of two parts, a "near-real-time" (hereafter "NRT") run and a forecast run. The NRT run employs the NCEP GFS (global forecast/analysis system, previously known as "AVN") data to run forward one day at a time as soon as the previous day's data are available. The forecast runs use the NCEP forecast data in place of the NCEP analysis. The NCEP data are made available daily via the internet (http:// www.nco.ncep.noaa.gov/pmb/products/avn). These data are

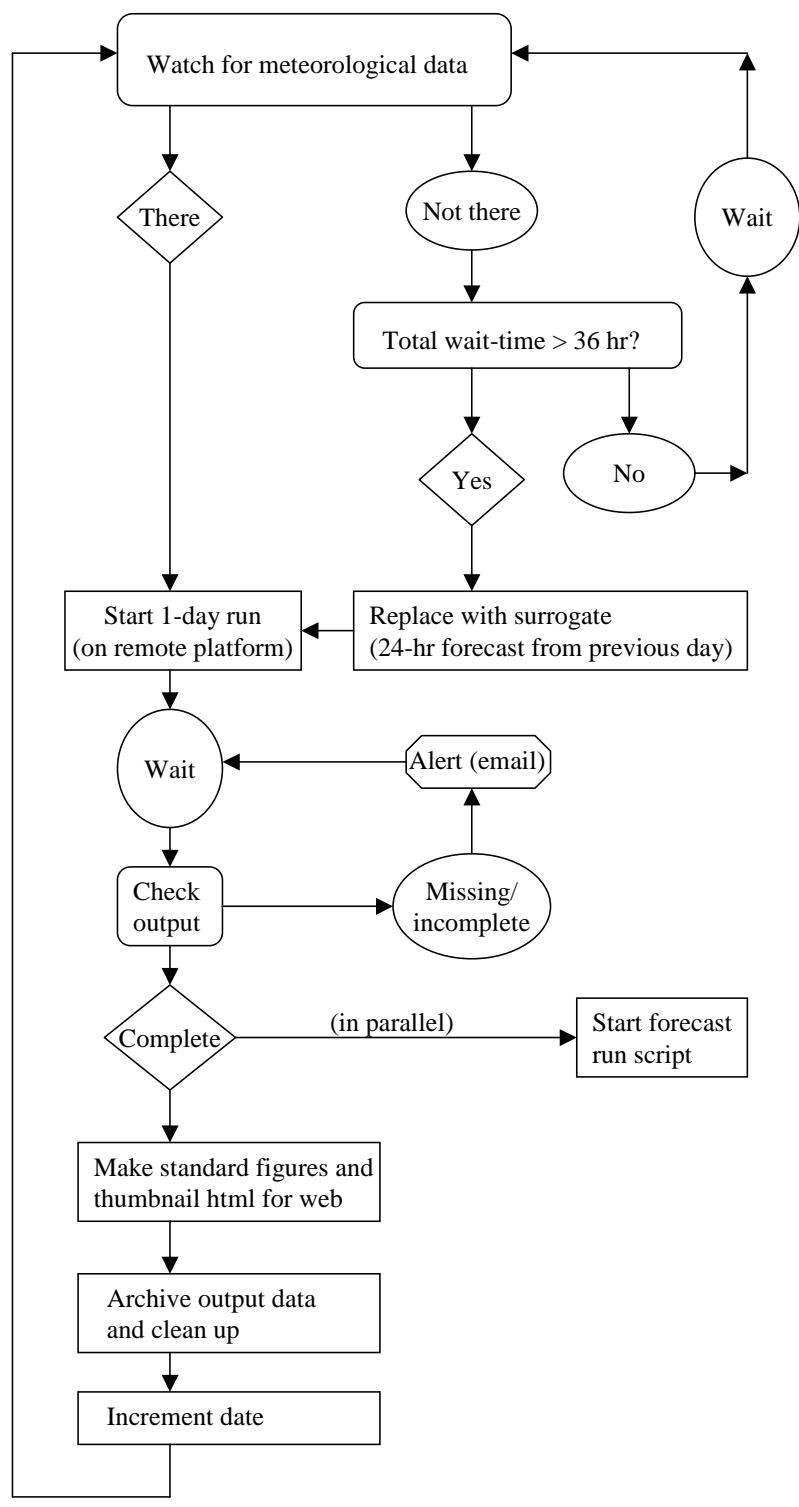

Fig. 1. Flowchart of the daily near real time and forecast runs procedure. The forecast run script follows the same procedure, except that no surrogates are used (the forecast run stops if the data does not become available). Within the fully-automated process there are several internal checks to ensure that the system is running as expected, with email alerts when problems arise.

retrieved at NCAR (Boulder) and interpolated from T170 $(256 \times 512$ grid points in latitude and longitude) to the reduced resolution data used for the runs in Mainz (currently $\mathrm{T} 42,64 \times 128$ grid points, or about $2.8^{\circ}$ in the horizontal, and 42 levels in the vertical up to about $2 \mathrm{hPa}$ ).

Once the data is transferred to Mainz, the daily NRT run starts up using the model restart file from the previous day and runs forward one day. If there is a delay in the data delivery, the NCEP forecast data from the previous day is used as a surrogate for the NCEP analysis. This prevents the fore- 
Table 2. Summary of the measurements techniques used for the observations considered in this paper

\begin{tabular}{|c|c|c|c|c|}
\hline Campaign & Gas & Instrument & Reference & Comments \\
\hline MINOS (Falcon) & $\mathrm{CO}$ & TDLAS $^{1}$ & Wienhold et al. (1998) & accuracy: $2 \%$, precision: $1.5 \%$ \\
\hline MINOS (Falcon) & $\mathrm{O}_{3}$ & UV-absorption & Schlager et al. (1997) & accuracy: $5 \%$, precision: $2 \%$ \\
\hline CONTRACE (Falcon) & $\mathrm{CO}$ & VUV-fluorescence & Gerbig et al. (1999) & accuracy: $5 \%$, precision: $2 \%$ \\
\hline CONTRACE (Falcon) & $\mathrm{O}_{3}$ & UV-absorption & Schlager et al. (1997) & accuracy: $5 \%$, precision: $2 \%$ \\
\hline INDOEX (Citation) & $\mathrm{CO}$ & TDLAS $^{1}$ & Wienhold et al. (1998) & accuracy: $10 \%$, precision: $10 \%$ \\
\hline INDOEX (ship) & $\mathrm{CO}$ & TDLAS $^{1}$ & Wienhold et al. (1998) & see Note 2 \\
\hline INDOEX (ship) & $\mathrm{O}_{3}$ & UV-absorption & Stehr et al. (2002) & see Note 3 \\
\hline
\end{tabular}

1 Tunable Diode Laser Absorption Spectrometer

2 Redundant measurements with the technique of Dickerson and Delany (1998) were also made and found to be in very close agreement.

3 Two identical instruments were used and were found to agree with each other to within $1 \%$ or $1 \mathrm{nmol} / \mathrm{mol}$; the data was corrected for line losses, and prior to the campaign a calibration against a NIST reference ozone detector agreed within $1 \%$.

cast system from falling too far behind or stopping during active campaigns. In 2001, surrogates were used about $10 \%$ of the time; in 2002 this was reduced to about $6 \%$ of the time.

After the NRT run for a day is finished, pre-selected figures are made and placed in the internet, the 3-hourly output data from MATCH-MPIC is archived, and the date is incremented to the next day. The archived output data is then available for making custom figures via the web interface. In parallel, the forecast run for the day is initialized using the restart file from the end of the day's NRT run, and steps forward like the analysis run procedure in Fig. 1. The automated runs and plots are normally done by about 06:00 UTC the next day, so that the 1-day forecast (which is actually for the current day) has been available in time for daily flight briefings for the three main campaigns participated in so far. In the discussion below we focus on the 2-day (48-hour) forecast fields; these are available about one day in advance after the computational lag time, and were generally the most critical for making the flight plans.

The present forecast system started with a prototype run at T21 resolution on 1 May 2001, with the tracer distributions initialized to the average for May 1998 from the base run in von Kuhlmann et al. (2003). On 1 June 2001, the forecast system was switched to T42 and has provided routine daily forecasts since. The model was thus given about three months to spin up before being used in the MINOS campaign (August 2001), and six months prior to CONTRACE (November 2001).

\section{Forecasts and observations during MINOS, CON- TRACE, and INDOEX}

3.1 Field campaign descriptions and measurement techniques

This section briefly describes the three field campaigns, the measurements techniques employed, and the chemical weather forecasts used in each campaign (meteorological forecasts were available for all campaigns, along with forward and backward trajectories).

MINOS (http://www.mpch-mainz.mpg.de/ $\sim$ reus/minos) was conducted during July and August 2001, in the eastern Mediterranean Sea. 14 research flights were made with the DLR Falcon based out of Heraklion, Crete. The objectives of MINOS included examining: (1) the transport of pollution to the Mediterranean region from Europe and from remote sources, especially Asia; (2) the chemical mechanisms involved in the build-up of oxidants and aerosols in the region; and (3) the export of pollutants to the global environment, e.g. towards Asia. Two chemical weather forecast systems were employed: (1) MATCH-MPIC and (2) regional CO tracers computed using the ECHAM5 GCM (see Appendix).

The CONTRACE program (http://www.pa.op.dlr.de/ contrace) focuses on the processes which control the transport of trace gases, especially $\mathrm{NO}_{x}$, to the free troposphere (FT) over Europe. The first field campaign (CONTRACE 1, hereafter simply CONTRACE) was in November 2001, and focused on frontal uplifting, including transport of pollutants from North America to Europe (Stohl, 2001). A second, planned for summer 2003, will focus on transport and scavenging by deep convection. Four flights (three of them two-part) with the DLR Falcon were conducted during CONTRACE, based out of Oberpfaffenhofen (near Munich, Germany). Three separate chemical weather forecasts were used in the flight planning: (1) the MATCH-MPIC forecasts, 
(2) $\mathrm{CO}$ tracer forecasts based on the FLEXPART Lagrangian particle dispersion model, and (3) regional $\mathrm{O}_{3}$-chemistry forecasts using the EURAD model (see the Appendix for FLEXPART and EURAD setups).

A prototype of the MATCH-MPIC forecast system was used during INDOEX (http://www-indoex.ucsd.edu), which took place in the Indian Ocean region during January-April 1999. The major objectives were to assess the degree of chemical pollution and its dispersion over the region, and to examine the role of continental aerosols in the regional radiative forcing (Crutzen and Ramanathan, 2001). Several observation platforms were involved, including two aircraft, two ships, several ground stations and satellites. The MATCHMPIC chemical weather forecasts were used in planning several flights of the Dutch Cessna Citation (de Gouw et al., 2001), based out of Malé ( $4^{\circ} \mathrm{N}$, capital of the Maldives). These forecasts were computed using an earlier version of MATCH-MPIC (v2.0, described in Lawrence et al., 1999), also used for INDOEX in Lal and Lawrence (2001), which differed from the current version mainly in its use of a simplified chemistry scheme which neglected NMHCs. This allowed a higher horizontal resolution (T62, about $\left.1.9^{\circ}\right)$ than the current system. The INDOEX forecasts were only computed from mid-February until the end of March 1999, with only a one-week spin-up period possible after initializing from the mean trace gas distributions computed for February 1993 (from Lawrence et al., 1999).

The measurements techniques used during these campaigns are described in Table 2. Only $\mathrm{CO}$ and $\mathrm{O}_{3}$ are considered here. During INDOEX there were no other gases that were measured on the aircraft which were also included in the model (except NO, which was generally below the detection limit of the instrument). The data on other gases observed during MINOS and CONTRACE and their comparison with the model output are still under evaluation, and will be discussed in several other manuscripts in this special issue. Generally the comparison with $\mathrm{CO}$ is good, while $\mathrm{O}_{3}$ and other gases often show the same types of problems as seen in evaluations of the chemical climate as simulated by global models (e.g. Emmons et al., 1997; Hauglustaine et al., 1998; Lawrence et al., 1999; Thakur et al., 1999).

3.2 Overview of the forecast applications during the three field campaigns

A summary of the flights for which the MATCH-MPIC forecasts played a primary role in determining the flight plans is given in Table 3, along with the correlation coefficients, RMS errors, and ratios between the mean modeled and observed $\mathrm{CO}$ mixing ratios. In every case the main predicted features in the trace gas distributions were observed. Not only were the forecasts successful in this overall sense, but they were also generally well-correlated with the observations on a flight-by-flight basis, with correlation coefficients $(r)$ for $\mathrm{CO}$ nearly always above 0.7 , and reaching as high as 0.96 . The RMS differences indicate that the variations (departures from the mean) in the modeled values were generally within $10-20 \%$ of the observed spatial and temporal variations. There is only a slight degradation in the correlations and RMS differences for the 2-day forecasts compared to the NRT run. MATCH-MPIC tended to underestimate the mean CO levels by about 25\% during INDOEX and overestimate by about $30 \%$ during CONTRACE, whereas it is in close agreement with the MINOS data. The reasons for these regional offsets are still unclear. They are likely due to errors in the emissions inventories, though this is difficult to determine definitively, since they are within the range of regional uncertainties in current emissions inventories. For the sake of flight planning, however, the reproduction of spatial and temporal variations (i.e. the correlation) is more important than prediction of absolute values. Note that the comparisons of MATCH-MPIC output with the observations were done by making "virtual flights" through the model output, interpolating it in 4-D space/time to the position of the aircraft during the flights. This places a greater demand on the model than the alternative of averaging the observations onto the model domain.

The rest of this section gives a brief description of the overall primary forecast applications during the three campaigns, based on Table 3 . In addition to the flights listed in Table 3, MATCH-MPIC forecasts played a secondary role in the planning of several other flights, especially during INDOEX, when the chemical weather forecasts were untested and more weight was normally placed on the traditional forecast products. Several flights were also guided by other criteria to which the forecast system described here did not apply, such as intercomparison flights between aircraft, and aerosol observations. A detailed description of the forecasts on a flight-by-flight basis, including the original forecast figures and comparisons to the observations for most of the flights, is available via http://www.mpch-mainz.mpg.de/ lawrence/ forecasts/flight_by_flight_imc/. The targeted features of the flights based on the chemical weather forecasts can be broken down into three basic types:

1. boundary layer and lower tropospheric outflow of pollution from nearby populated regions (all three campaigns),

2. intercontinental pollution plumes (MINOS and CONTRACE only), and

3. separation of the chemical northern and southern hemispheres by the intertropical convergence zone (INDOEX only).

The flights of the first type, observing near-surface pollution outflow, showed that while global chemical weather forecasts are able to predict the general regions where enhanced mixing ratios should be seen on a day-to-day basis, such flights would benefit from higher resolution or from regional model forecasts. The plans for this flight type were in 
Table 3. Summary of MATCH-MPIC forecasts and statistics of the comparisons between the modeled and observed CO mixing ratios

\begin{tabular}{|c|c|c|c|c|c|c|}
\hline $\begin{array}{l}\text { Flight } \\
\text { (date+leg) }\end{array}$ & Forecasted/Observed Features & $\begin{array}{c}r \\
\text { NRT Run }\end{array}$ & $\begin{array}{c}r \\
\text { 2-day Fcst }\end{array}$ & $\begin{array}{l}\operatorname{RMS}^{1}(\%) \\
\text { NRT Run }\end{array}$ & $\begin{array}{l}\operatorname{RMS}^{1}(\%) \\
\text { 2-day Fcst }\end{array}$ & $\begin{array}{l}\text { Ratio }^{2}: \\
\bmod / \mathrm{obs}\end{array}$ \\
\hline \multicolumn{7}{|l|}{ MINOS } \\
\hline \multirow[t]{2}{*}{ 20010801a } & Asian Plume and European Outflow & 0.96 & 0.96 & 9.7 & 10.0 & 1.01 \\
\hline & Only data above $4 \mathrm{~km}^{3}$ : & 0.63 & 0.70 & 7.0 & 6.4 & 0.95 \\
\hline \multirow[t]{2}{*}{$20010803 a$} & Asian Plume and European Outflow & 0.68 & 0.73 & 26.9 & 29.8 & 1.07 \\
\hline & Only data above $4 \mathrm{~km}^{3}$ : & 0.58 & 0.65 & 13.2 & 13.0 & 0.91 \\
\hline \multirow[t]{2}{*}{$20010808 \mathrm{a}$} & Asian Plume & -0.021 & -0.002 & 9.0 & 9.3 & 0.96 \\
\hline & Only data above $4 \mathrm{~km}^{3}$ : & 0.55 & 0.53 & 4.7 & 5.2 & 0.98 \\
\hline $20010812 \mathrm{a}$ & European Plume east of Italy & 0.70 & 0.66 & 20.3 & 22.8 & 0.98 \\
\hline $20010819 b$ & $\begin{array}{l}\text { European Plume east of Italy, } \\
\text { East-West Gradient }\end{array}$ & 0.88 & 0.90 & 17.2 & 17.5 & 1.05 \\
\hline \multicolumn{7}{|l|}{$\underline{\text { CONTRACE }}$} \\
\hline 20011114a & Frontal Lifting near Corsica & 0.83 & 0.81 & 25.2 & 23.6 & 1.34 \\
\hline $20011114 b$ & Frontal Lifting near Corsica and over Italy & 0.80 & 0.78 & 17.6 & 16.4 & 1.29 \\
\hline 20011119a & North American Plume over Scandinavia & 0.79 & 0.74 & 13.6 & 15.0 & 1.32 \\
\hline $20011119 b$ & North American Plume over Scandinavia & 0.89 & 0.90 & 19.6 & 17.4 & 1.32 \\
\hline $20011127 \mathrm{a}$ & North American Plume over western Europe & 0.79 & 0.77 & 23.2 & 18.0 & 1.28 \\
\hline \multicolumn{7}{|l|}{ INDOEX } \\
\hline $19990304 a, b, c$ & $\begin{array}{l}\text { ITCZ close to Malè, } \\
\text { Sampled Meteorological Southern Hemisphere }\end{array}$ & 0.78 & 0.79 & 16.1 & 15.9 & 0.68 \\
\hline 19990319a & Gradient between Sri Lanka and Malè & 0.70 & 0.70 & 21.6 & 21.7 & 0.85 \\
\hline $19990321 a, b$ & Gradient between Sri Lanka and Malè & 0.75 & 0.70 & 12.2 & 12.9 & 0.76 \\
\hline
\end{tabular}

1 The relative root mean square differences are computed using the differences from the respective mean mixing ratios for each flight, i.e. $\frac{1}{<x>} \sqrt{\frac{\sum\left[\left(x_{i}-<x>\right)-\left(y_{i}-<y>\right)\right]^{2}}{N}}$, where $i$ are the samples and the sum goes from 1 to $N$, the $x_{i}$ and $y_{i}$ are the observed and modeled CO mixing ratios for each sample along the flight path, and $\langle x\rangle$ and $\langle y\rangle$ are the observed and modeled mean CO mixing ratios for the flight.

2 Ratio of the modeled to observed mean CO mixing ratios.

3 See the text for discussion of the correlations above $4 \mathrm{~km}$; for the flight on 8 August, the poor correlations for the full vertical profile (i.e., including the data below $4 \mathrm{~km}$ ) are due to a CO-rich layer at $3 \mathrm{~km}$ which was missed by the model (see Fig. 9d).

principle similar for INDOEX and MINOS, since both campaigns were based on islands in the outflow of major population centers. Both aimed for regions where the outflow was predicted to produce a considerable enhancement in the levels of key trace gases (e.g. CO) above the background values. Two such flights during INDOEX and four during MINOS were carried out based on the chemical weather forecasts. On all the flights, the pollutant outflow gradients were observed in the regions where they were predicted. However, especially during MINOS some of the smaller scale details were missed in the forecasts. For instance, the flight on 19 August targeted a large-scale gradient towards higher CO levels in the east, based on the MATCH-MPIC forecasts. This overall gradient was observed, but a thin plume $\left(\sim 1.1^{\circ}\right.$ width in longitude) of enhanced $\mathrm{CO}$ was also observed in the $\mathrm{BL}$, which neither MATCH-MPIC nor ECHAM was able to resolve (the horizontal resolution of both models was $\mathrm{T} 42, \sim 2.8^{\circ}$ ). In this case, a higher resolution regional model may have been able to simulate this feature better.

The advantages of a higher resolution regional model were also seen during the 14 November CONTRACE flights, which targeted European pollution lofted to the FT near a trough in the western Mediterranean. All three chemical weather forecasts (MATCH-MPIC, FLEXPART, and EURAD) predicted enhanced trace gas mixing ratios up to $500 \mathrm{hPa}$ in the region. However, only the regional model (EURAD) was able to predict strong enhancements in $\mathrm{CO}$ observed at 4-7 km along the flight path, due to outflow from local convection; both MATCH-MPIC and FLEXPART misplaced the convection too far to the west of Corsica (note that in both models the convection is re-diagnosed based on the basic meteorological data, and is not taken directly from 

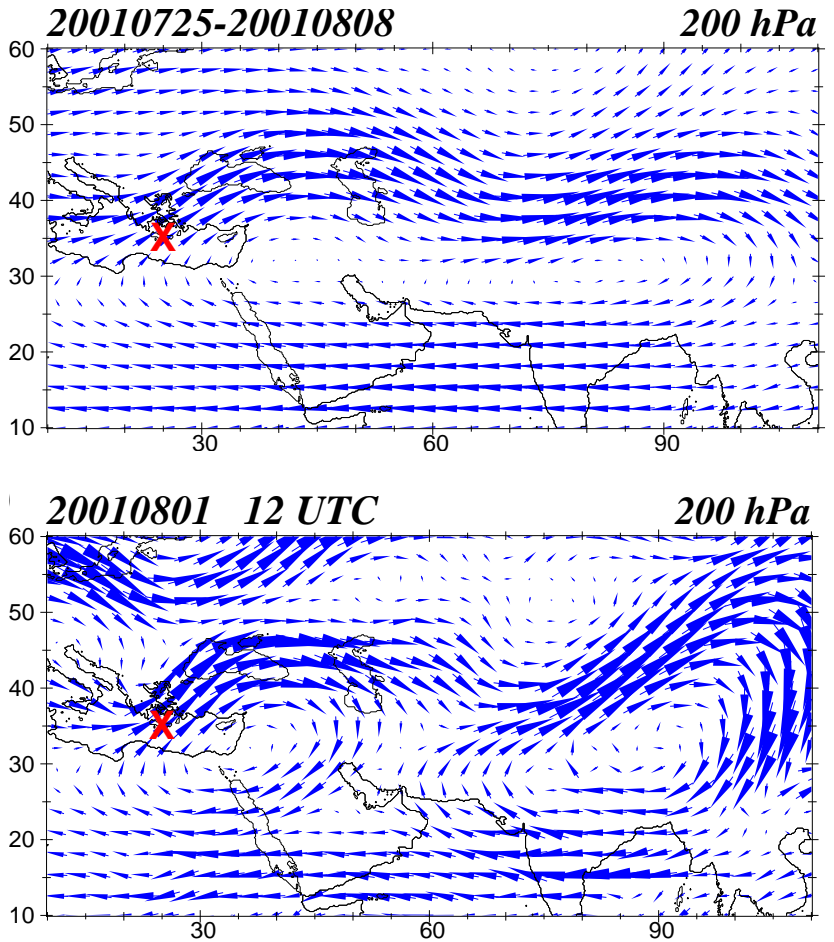

Fig. 2. NCEP AVN winds at $200 \mathrm{hPa}$ used to drive the MATCHMPIC runs: (a) average over the 2-week period up to the third MINOS flight (on 8 August); (b) instantaneous winds for 12:00 UTC, 1 August (date of the first MINOS flight). The " $\mathrm{X}$ " marks Crete.

NCEP; see the appendix for further information). The degree to which higher resolution regional models can consistently provide better forecasts of local convection effects than global models will be important to assess as more data becomes available from chemical weather forecasts for recent and future field campaigns.

Global chemical weather forecasts, on the other hand, have the advantage of being able to predict intercontinental plume transport (supporting the third type of flights), which is generally not possible with regional models. During MINOS the summer monsoon outflow from southern Asia was observed on three flights based on the MATCH-MPIC and ECHAM forecasts. Three plumes from North America were observed during CONTRACE with support from the MATCH-MPIC and FLEXPART forecasts. These plumes and the model results are discussed in detail in the following two sections. Furthermore, the MATCH-MPIC forecasts were at a sufficient horizontal resolution to be able to predict the location of the sharp trace gas gradients between the northern and southern hemisphere at the intertropical convergence zone (ITCZ) during INDOEX, which is discussed in the final section below.

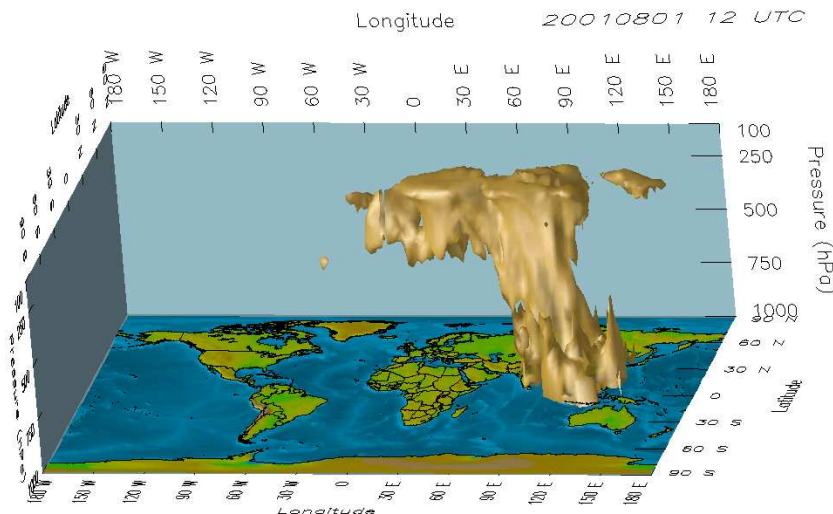

Fig. 3. 3-D structure of the southern Asian CO tracer from MATCH-MPIC (NRT run) at 12:00 UTC on 1 August 2001; the shaded region depicts mixing ratios above $25 \mathrm{nmol} / \mathrm{mol}$.

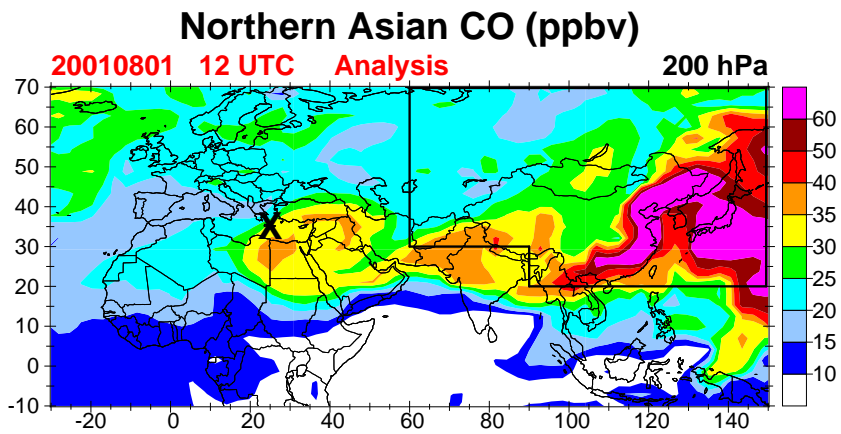

Southern Asian CO (ppbv)

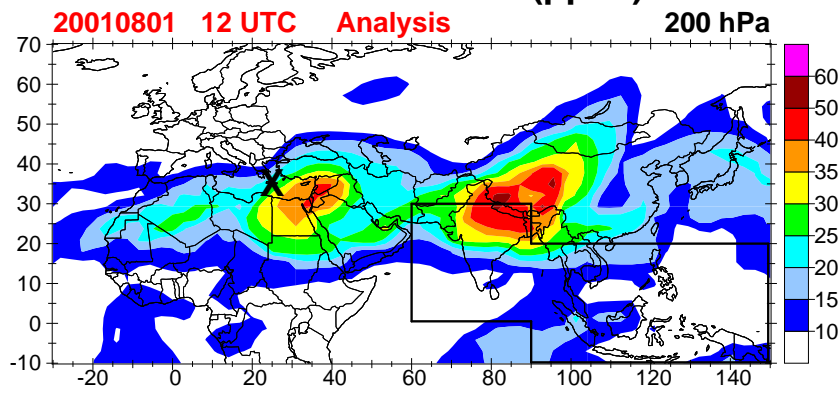

Fig. 4. Distributions of the (a) northern Asian and (b) southern Asian CO tracers at $200 \mathrm{hPa}$ from MATCH-MPIC (NRT run) at 12:00 UTC on 1 August 2001. The "X" marks Crete, and the boxes delineate the regions where each $\mathrm{CO}$ tracer is emitted (at the surface). An animated version of this figure is available in the supplementary material - http://www.copernicus.org/EGU/acp/acp/3/267/ acp-3-267_supp.zip (12MB).

\subsection{The Asian monsoon plume during MINOS}

Every year during the summer monsoon period in Asia, deep convection lofts insoluble and moderately soluble pollutants from populated regions of southern Asia (especially India) into the upper troposphere (UT). These UT outflow plumes 

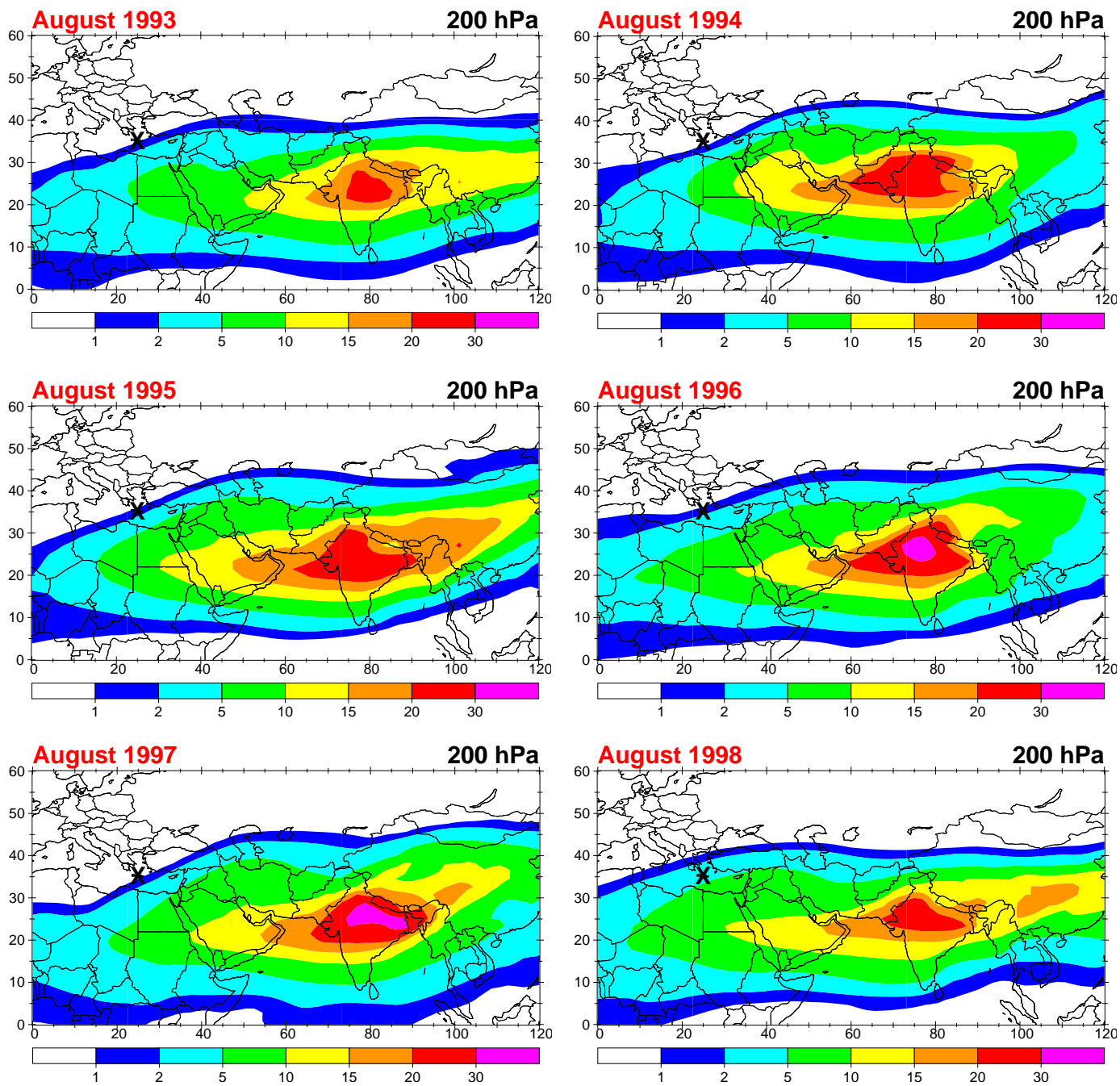

Fig. 5. 6-year climatology of a southern Asian CO-like tracer at $200 \mathrm{hPa}$ in August based on MATCH-MPIC, used in the pre-campaign planning phase of MINOS; the tracer had the same emissions as CO but a constant 30-day lifetime everywhere, and the runs were driven by the NCEP reanalysis data (as used in Lawrence et al., 1999), rather than the NCEP AVN analysis data used for the forecast system described here.

are then frequently carried towards Africa by the tropical easterly jet on the southern side of the upper level Tibetan anticyclone (Fig. 2), then northwards over the Mediterranean at the western edge of an anticyclone over northern Arabia which is part of the Walker circulation in this region (Das, 1992). The locations of the Tibetan and Arabian UT anticyclones depicted in Fig. 2b vary, so that in the mean they form a large anticyclone covering the region from Tibet to the eastern Mediterranean (Fig. 2a). An example of the threedimensional structure of the outflow plume resulting from this circulation is shown in Fig. 3; the plume is often present as an elongated, contiguous region of enhanced $\mathrm{CO}$ levels, mainly between $400-150 \mathrm{hPa}$.

The separation of the plume into the southern Asian and northern Asian CO tracers in MATCH-MPIC at $200 \mathrm{hPa}$ is shown in Fig. 4 (see the supplementary material for an ani- mation of this figure). In the MATCH-MPIC forecast runs, the northern Asian CO tracer was defined as two rectangles so that it included all of China (Table 1). This results in the northern Asian tracer being split into two outflow regions in the upper troposphere: to the east, Chinese emissions are transported to the UT by deep convection over the Pacific warm pool, and then carried in westerlies which are sufficiently strong to circle the globe and influence the UT CO levels over continental Europe; convection over southern China feeds the easterlies of the Tibetan anticyclone, so that the northern Asian $\mathrm{CO}$ merges with the southern Asian CO plume over the Bay of Bengal and India. In our analysis of the southern Asian plume during MINOS with MATCH-MPIC, we have found that in most cases the northern Asian and southern Asian CO tracers contribute roughly equal amounts to the total $\mathrm{CO}$. Since the partitioning into 


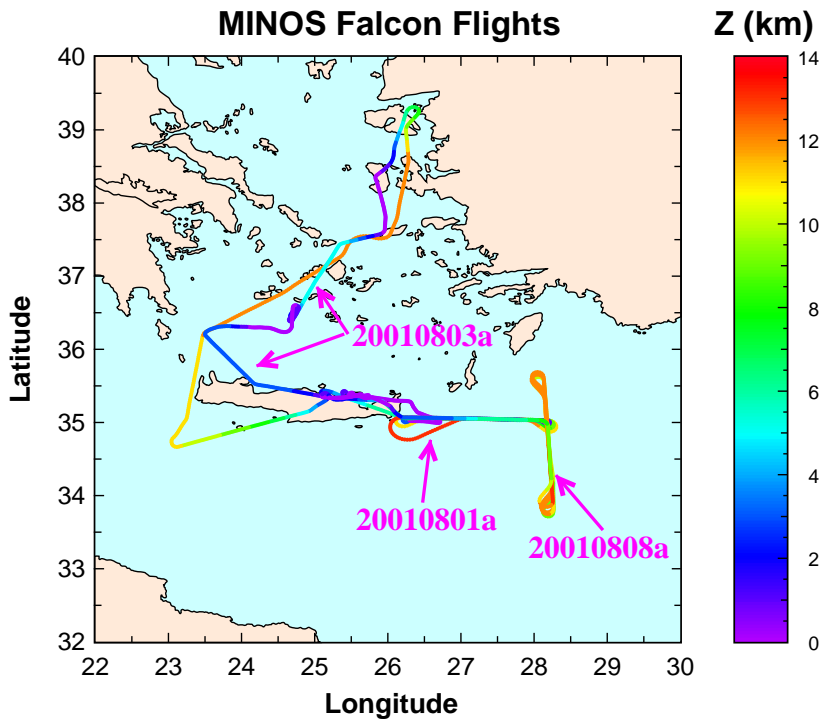

Fig. 6. The flight routes for the MINOS flights on 1, 3, and 8 August 2001. The routes are labeled by the date (YYMMDD), and by the flight leg ( $\mathrm{a}$ in all three cases). The color coding indicates the altitude.

northern and southern tracers is rather arbitrary, in the analysis of the forecast model results below only the sum of the two Asian tracers will be examined.

Based on analyses of multi-year wind fields, trajectories, and tracer simulations, it was hypothesized that the southern Asian monsoon outflow could be observed over the eastern Mediterranean; this was one of the objectives of MINOS. The chemical nature of the plume is being analyzed by Scheeren et al. (2003). Here we concentrate on the plume's spatial distribution, the comparison of model output with the observations, and the frequency of strong plume events in the region.

Figure 5 shows a six year climatology of the UT distribution of a CO-like tracer from India which was used in planning MINOS, based on a high resolution (T63) run done prior to MINOS with an earlier version of MATCH-MPIC (in that run, only a southern Asian component was included). The outflow to the west is directed mostly towards Arabia and northeast Africa; there is also a considerable dispersion of the plume to the east. In most years the monthly average extent of the plume just barely reaches Crete, due to the northern Arabian UT anticyclone (Fig. 2) which brings airmasses northwards from Africa to the eastern Mediterranean, with the furthest northwest extent of the trajectories being close to Crete. There is, however, a significant interannual variability, with the average plume extending well past Crete in 1998. There is also a large day-to-day variability in the plume's location and its $\mathrm{CO}$ mixing ratios (see the animation of Fig. 4 in the supplementary material). Such plumes would be difficult to predict with standard meteorological fields or forward trajectories, since the plume depends on the integrated ef-
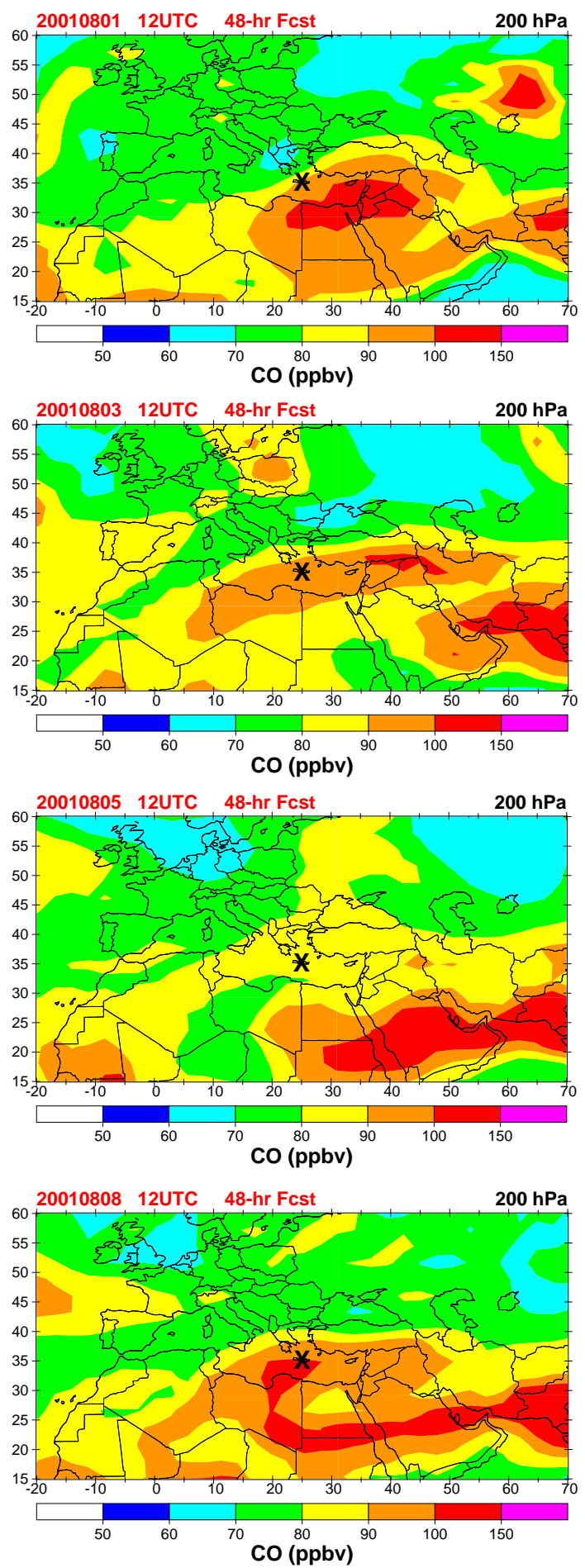

Fig. 7. $\mathrm{CO}$ mixing ratios $(\mathrm{nmol} / \mathrm{mol})$ at $200 \mathrm{hPa}$ predicted by MATCH-MPIC (2-day forecasts) for 12:00 UTC on (a) 1 August, (b) 3 August, (c) 5 August, and (d) 8 August, 2001. These are the same figures as those which were used in the field, giving a direct impression of the information which was available for the flight planning. 
CO tracers [ppb] for 12Z01AUG2001

MPIfM Hamburg/ECMWF ECHAM5 forecast product, initialized $2001073012 Z$

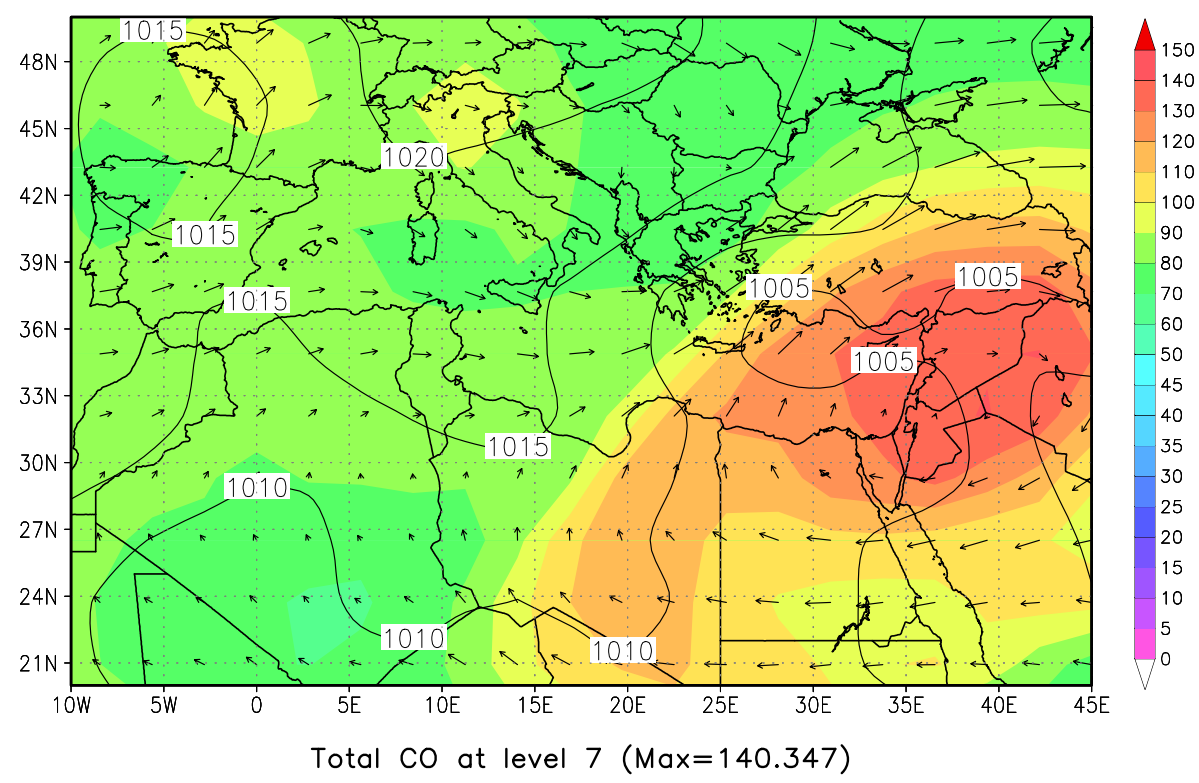

Fig. 8. $\mathrm{CO}$ mixing ratios (nmol/mol) at about $200 \mathrm{hPa}$ (model level 7) predicted by ECHAM (2-day forecasts) for 12:00 UTC on 1 August 2001. The figure has been remade post-campaign with modified contours to facilitate comparison with MATCH-MPIC. fects of: the strength of convection over Asia 5-7 days back, the strength and location of the Tibetan and northern Arabian anticyclones, the transport times (aging of the plume), and dilution due to mixing with other UT air masses. Thus, the chemical weather forecasts during MINOS were central to achieving the objective of observing the plume.

Three flights to examine the plume were conducted on 1, 3 , and 8 August 2001. The first and third flights were conducted to the east of Crete, while the second was to the north (Fig. 6). Selected MATCH-MPIC forecast figures which were used in planning these flights are shown in Fig. 7. The forecasts indicate a region of measurable enhancements $(\sim 20 \mathrm{nmol} / \mathrm{mol}$ over the background) to the south and east of Crete on 1 August, which advanced to the north on 3 August. By 5 August, the strong plume had passed by, but the next one reached Crete prior to the third flight on 8 August. The Asian $\mathrm{CO}$ tracers (see Fig. 4 for an example) showed similar patterns of enhanced values on the flight days. The ECHAM forecasts were generally in good agreement with MATCHMPIC; Fig. 8 shows an example for 1 August. The differences are relatively small in light of the different wind fields, emissions, and treatments of CO chemistry ("online" vs. "offline"). The Asian plume forecasts and the overall similarity between the two models resulted in three flights being conducted to intersect the plume.

The observed and modeled vertical profiles, shown in Fig. 9, all indicate an enhancement in UT CO compared to the middle troposphere during each of the flights. In the first and third flights, the enhanced $\mathrm{CO}$ levels extend from about $8-13 \mathrm{~km}$, while in the second flight the plume was only clearly observed above about $10 \mathrm{~km}$. In all the profiles the observed enhancement is $\sim 30-50 \mathrm{nmol} / \mathrm{mol}$ (from values of $\sim 70-80 \mathrm{nmol} / \mathrm{mol}$ below the plume to values of $\sim 100$ $120 \mathrm{nmol} / \mathrm{mol}$ in the plume). These enhancements are also statistically significant in comparison to the typical UT CO levels in this region; Lelieveld et al. (2002) (in their Fig. 2) showed that the mean $\mathrm{CO}$ for these three flights above $8 \mathrm{~km}$ exceeded one standard deviation above the mean UT CO averaged over all 14 MINOS flights. The modeled enhancements are weaker $(\sim 10-20 \mathrm{nmol} / \mathrm{mol}$, with the exception of ECHAM for the 8 August flight), and generally limited to being above about $10 \mathrm{~km}$. However, as will be shown below, the model shows clear plume signatures during the periods that the enhanced values were measured. Furthermore, for these three flights, the regressions have also been computed for only the region above $4 \mathrm{~km}$ (Table 3); this results in correlation coefficients averaging 0.59 for the NRT run and 0.63 for the forecasts, and relative RMS deviations which are somewhat smaller than for the full vertical profiles. The MATCH-MPIC tracers (and the ECHAM tracers, not shown) attribute the enhanced UT CO levels to largely being due to Asian emissions. Since, as discussed above, several factors control the amount of Asian $\mathrm{CO}$ which reaches the UT near Crete, it is not clear what causes the models to generally underestimate the degree of enhancement in the plumes (compared to the middle troposphere).

Several other interesting features are also present, such as the near-surface enhancements originating from eastern $\mathrm{Eu}$ rope, and the convective outflow near $5 \mathrm{~km}$ on 1 and 3 August with western and eastern European origins. North American $\mathrm{CO}$ also has a substantial influence in this region up to $8 \mathrm{~km}$ according to MATCH-MPIC (shown for 8 August in Fig. 9d, 

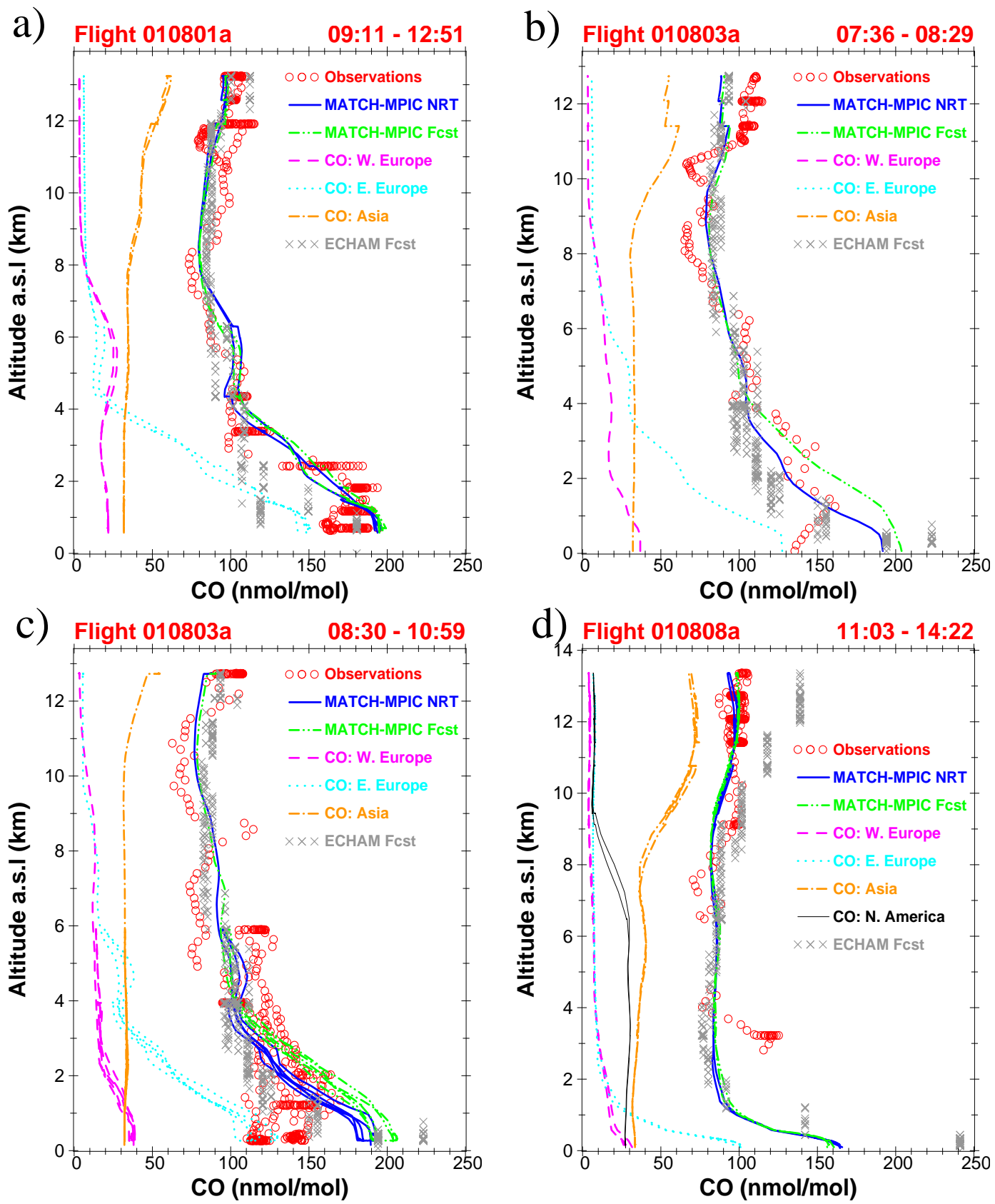

Fig. 9. Vertical profiles of observed CO mixing ratios (nmol/mol), along with the model output (MATCH-MPIC and ECHAM) corresponding to the flight trajectories for the MINOS flights; the MATCH-MPIC CO is shown for both the near real time (NRT) run and the 2-day forecasts (Fcst), and also includes the regional CO tracers (NRT run) for Western Europe, Eastern Europe, Asia and North America (only panel d). (a) Flight 1 on 1 August, (b) Flight 2 on 3 August, outbound leg, (c) Flight 2 on 3 August, return leg, (d) Flight 3 on 8 August. The date and the time range during which each profile was observed is given above each panel. The MATCH output is interpolated in time and space to the flight location every 15 seconds. The ECHAM output is not interpolated, but instead uses the nearest neighbors in time and space; the model levels above and below the observations were both plotted if the flight level was more than $30 \mathrm{hPa}$ away from the nearest model level.

also similar for the earlier flights). The North American CO decreases over the same altitude range as the Asian CO contribution is increasing, resulting in roughly constant modeled total $\mathrm{CO}$ between $8-9 \mathrm{~km}$. It is remarkable that above about $2 \mathrm{~km}$ during the third flight, the total $\mathrm{CO}$ is dominated by emissions from outside Europe. During the earlier flights (Fig. 9a-c), the European CO emissions contributed substantially up to about $6 \mathrm{~km}$, but above this the $\mathrm{CO}$ from other regions again dominated. The extent and implications of this strong influence of intercontinental transport to the Mediter- 

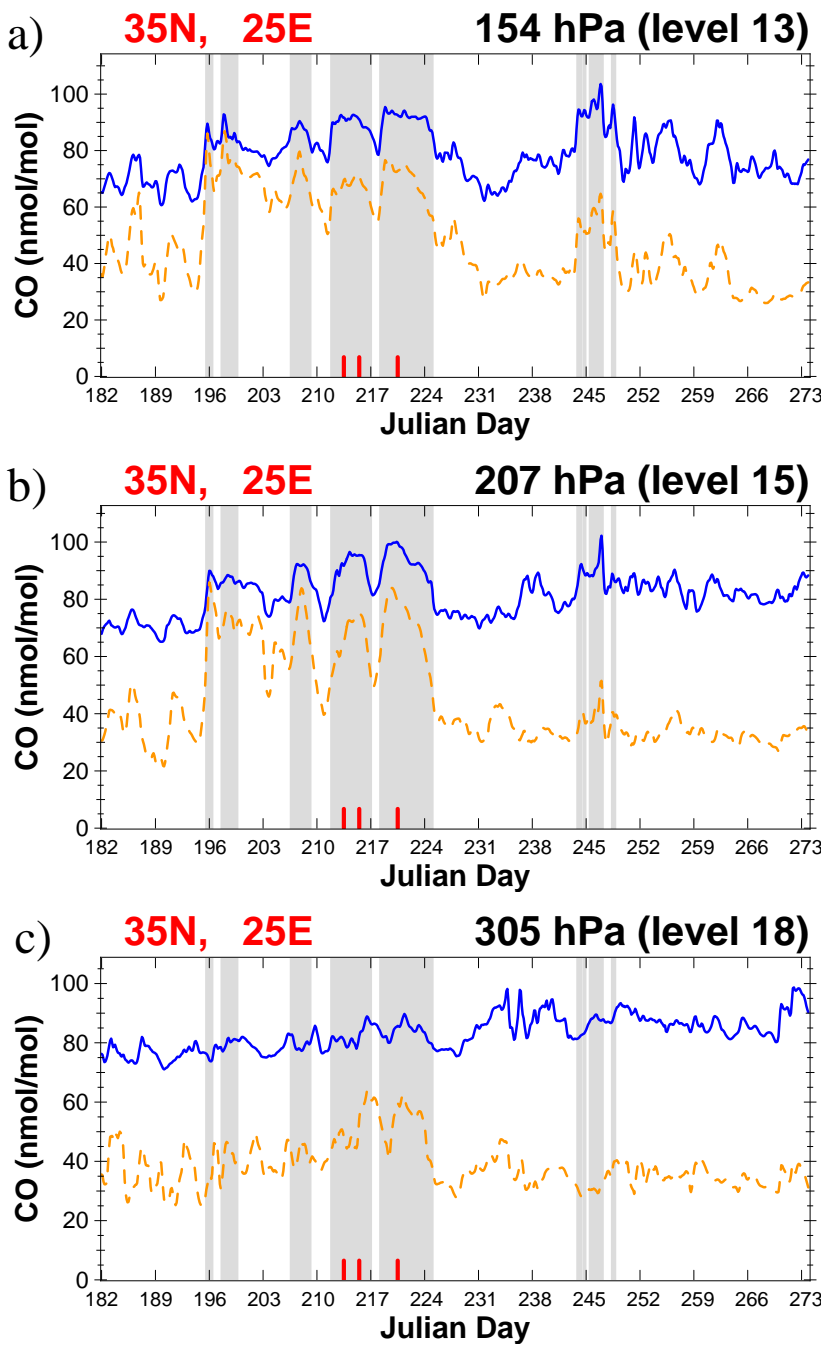

Fig. 10. Mixing ratios (nmol/mol) of $\mathrm{CO}$ (blue, solid line) and the Asian CO (orange, dashed line) over Crete from 1 July 2001 (Julian Day 182) to 30 September 2001 (Julian Day 273) at (a) model level $13(\sim 150 \mathrm{hPa}),($ b) model level $15(\sim 200 \mathrm{hPa})$, (c) model level 18 $(\sim 300 \mathrm{hPa})$ computed by MATCH-MPIC (NRT run). The flights on 1, 3, and 8 August are marked with red dashes. The shaded regions indicate times when a strong plume was present in the column (with $\mathrm{CO}_{t}=25 \mathrm{nmol} / \mathrm{mol}$, see the text for details). Since the $\mathrm{CO}$ tracers were still undergoing spin-up (they were initialized to zero on 1 May), they have been normalized (detrended) so that the total global mass of all the tracers together sums to $80 \%$ of the total CO mass, assuming that $\sim 20 \%$ of the global CO burden is from the oxidation of $\mathrm{CH}_{4}$ and other hydrocarbons.

ranean region are discussed in Lelieveld et al. (2002).

How frequently was this plume present over Crete and the surrounding region during MINOS and the months before and after? Figure 10 shows the time series of $\mathrm{CO}$ and the Asian CO tracers above Crete during July-September 2001, based on the MATCH-MPIC NRT run output (the 2-day forecast time series values are hardly discernible from the NRT

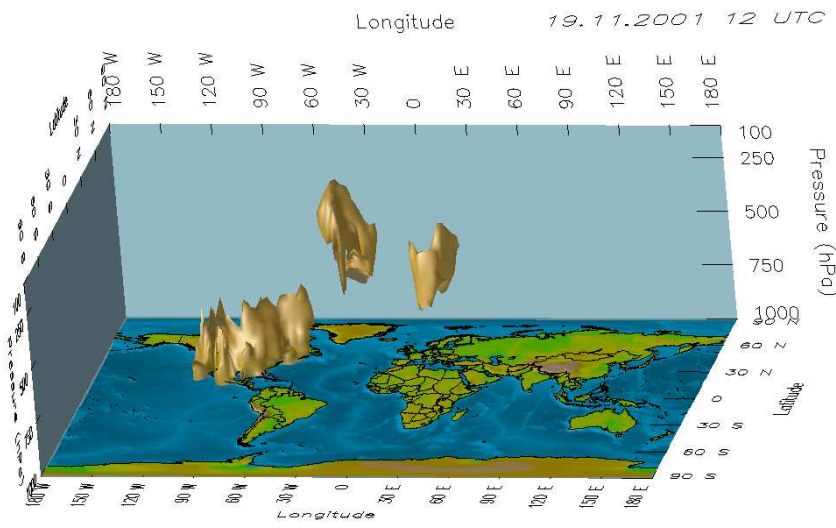

Fig. 11. 3-D structure of the North American $\mathrm{CO}$ tracer from MATCH-MPIC (NRT run) at 12:00 UTC on 19 November 2001; the shaded region depicts mixing ratios above $70 \mathrm{nmol} / \mathrm{mol}$.

Table 4. Percentages of time that strong Asian plumes were present in the Mediterranean region and strong North American plumes were present over northern Europe, based on various exceedence thresholds

\begin{tabular}{lccc}
\hline \multicolumn{3}{l}{$\mathrm{CO}_{t}^{1}$} \\
Location & 20 & 25 & 30 \\
\hline MINOS & & & \\
Crete & 38.6 & 22.7 & 12.1 \\
Crete $+10^{\circ} \mathrm{E}$ & 63.0 & 41.8 & 20.4 \\
Crete $+10^{\circ} \mathrm{S}$ & 51.2 & 32.3 & 20.1 \\
& 25.0 & 8.7 & 3.0 \\
CONTRACE & & & \\
Stockholm & 10.9 & 2.2 & 1.5 \\
Copenhagen & 13.6 & 5.3 & 2.2 \\
Munich & 16.0 & 6.0 & 1.8 \\
Brussels & 18.9 & 10.9 & 3.4 \\
\hline
\end{tabular}

1 Threshold exceedence value $\left(\mathrm{CO}_{t}\right)$ in nmol/mol (see text for details).

run, and are not plotted). We define a "strong plume" in a given model layer as any time the total $\mathrm{CO}$ and the Asian $\mathrm{CO}$ both exceed the 3-month minimum value in that layer by more than an arbitrary threshold value, $\mathrm{CO}_{t}$, where the minimum value is taken to be representative of the background $\mathrm{CO}$ levels, and $\mathrm{CO}_{t}$ is chosen to be between $20-30 \mathrm{nmol} / \mathrm{mol}$ (representing a clearly discernible signal in the measurements). The presence of a strong plume in the column is then defined as any time this criterion is met at any model level. The periods of a strong plume in the column above Crete (with $\mathrm{CO}_{t}=25 \mathrm{nmol} / \mathrm{mol}$ ) are indicated on Fig. 10 as regions of gray shading. Using this threshold, a strong plume 


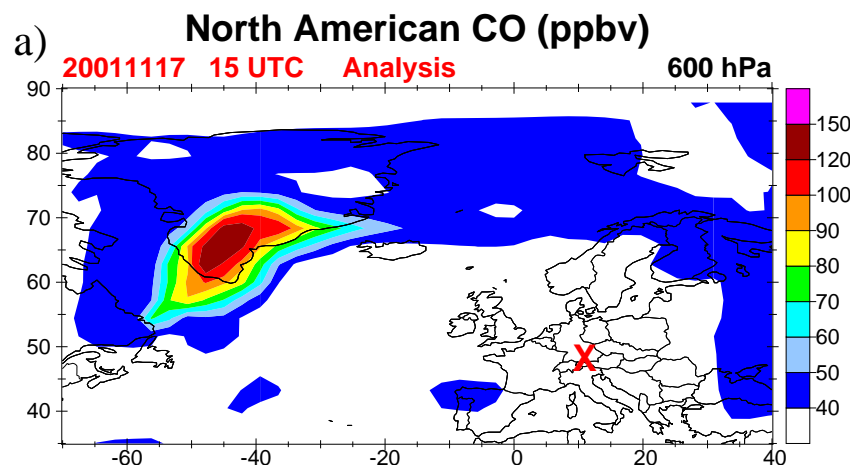

b)

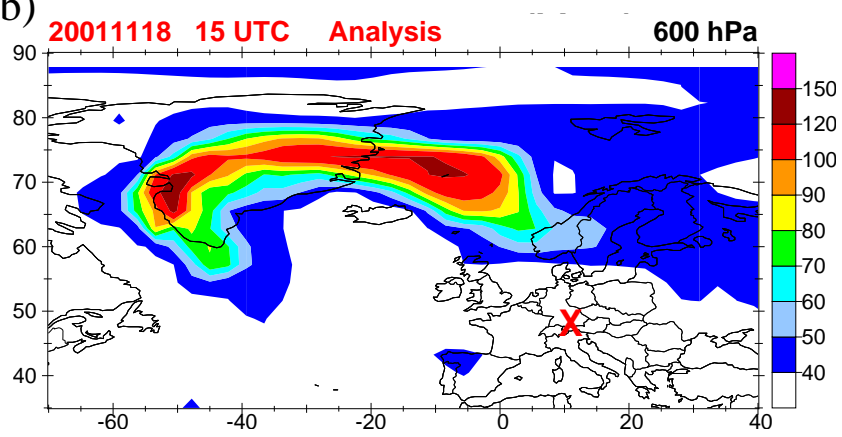

c)

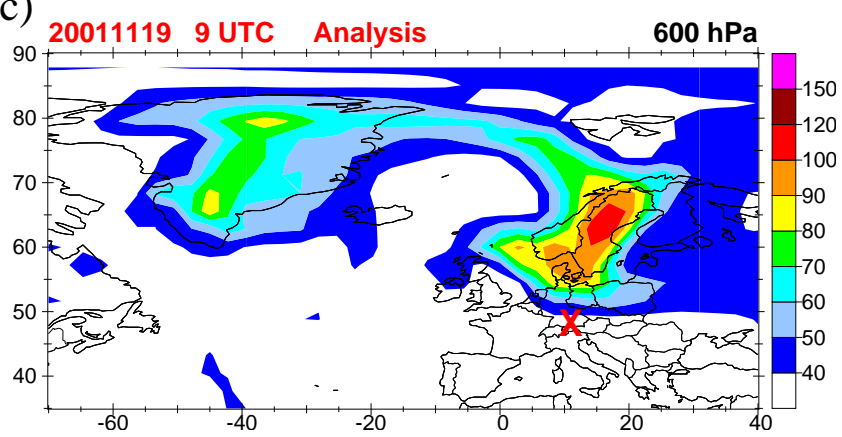

d)

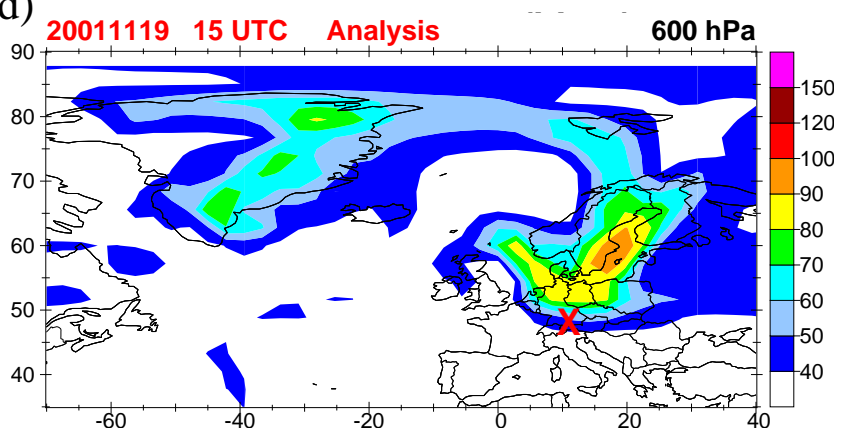

Fig. 12. Distributions of the North American CO tracer at $600 \mathrm{hPa}$ from MATCH-MPIC (NRT run) at (a) 15:00 UTC on 17 November 2001, (b) 15:00 UTC on 18 November 2001, (c) 09:00 UTC on 19 November 2001, and (d) 15:00 UTC on 19 November 2001. The "X" marks Oberpfaffenhofen. An animated version of this figure is available in the supplementary material - http://www.copernicus. org/EGU/acp/acp/3/267/acp-3-267_supp.zip. a)

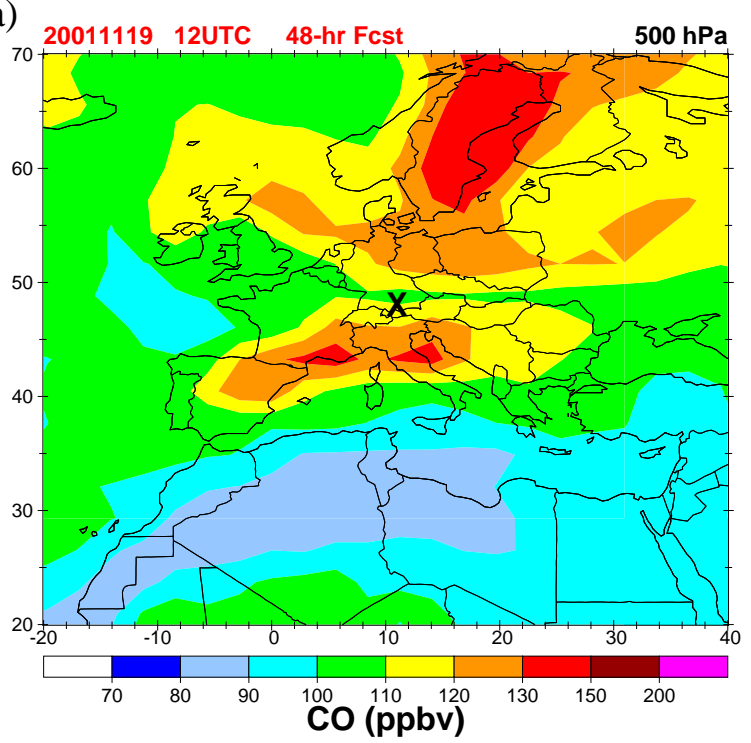

b)

CO MIXING RATIO IN $500 \mathrm{hPa}$

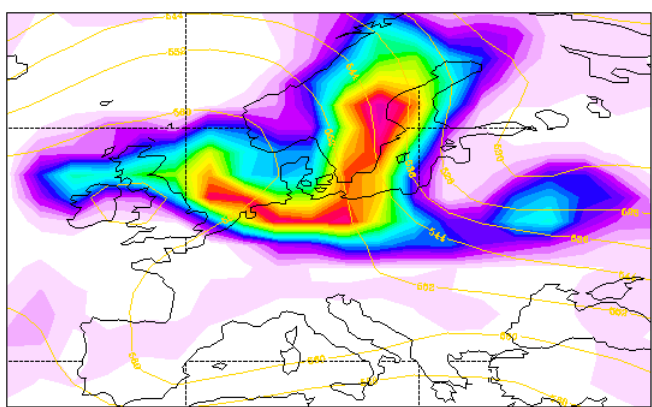

Maximum value $=64.8$

DATE $20011117 \quad 12+48$ HRS

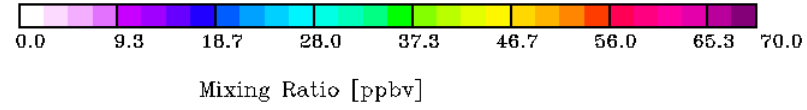

Fig. 13. Forecasted distributions of (a) CO predicted by MATCHMPIC and (b) North American CO tracer predicted by FLEXPART (2-day forecasts) for 12:00 UTC on 19 November 2001 , at $500 \mathrm{hPa}$. The "X" marks Oberpfaffenhofen.

is present above Crete $23 \%$ of the time. Table 4 lists the percentages for $\mathrm{CO}_{t}$ values of 20,25 and $30 \mathrm{nmol} / \mathrm{mol}$, as well as for the locations $10^{\circ}$ east, south, and west of Crete. South and east of Crete the strong plumes are more frequent; $10^{\circ}$ east of Crete, with $\mathrm{CO}_{t}=25 \mathrm{nmol} / \mathrm{mol}$, the plume is present over $40 \%$ of the time during the three months. To the west of Crete, enhancements of up to $20 \mathrm{nmol} / \mathrm{mol}$ are still common $(25 \%$ of the time), but more substantial enhancements of $25-30 \mathrm{nmol} / \mathrm{mol}$ are rare.

Focusing specifically on the role of the chemical weather forecasts, a strong plume was present over Crete for much of the period between Julian Day 196 (15 July) and 224 (12 
CONTRACE Falcon Flights, 20011119 Z (km)

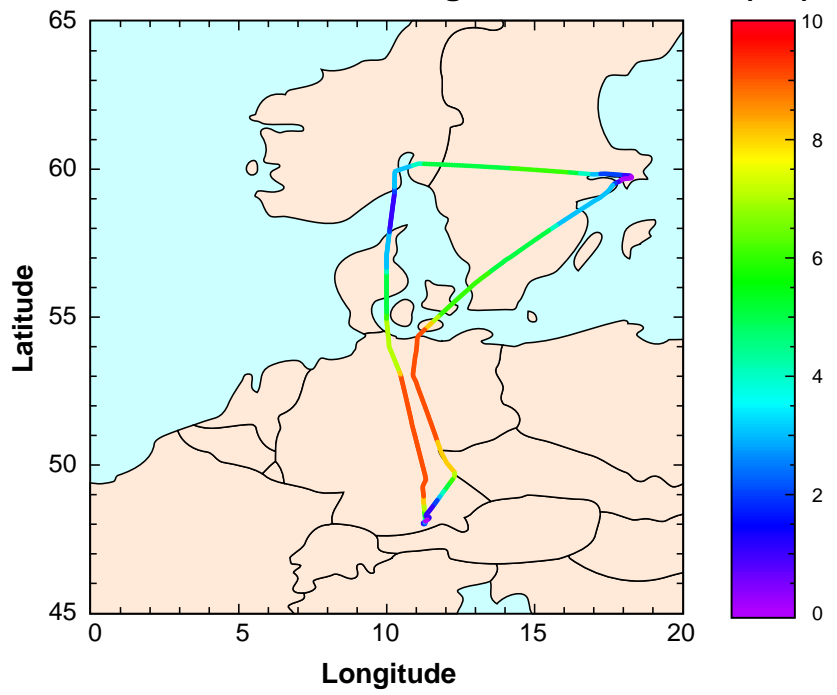

Fig. 14. The route of the CONTRACE flight on 19 November 2001, color coded by altitude.

August), confined mostly to the model levels above $300 \mathrm{hPa}$. The most persistent presence of the plume and its greatest vertical extent (down to $\sim 400 \mathrm{hPa}$ ) was during the first week of MINOS flights (starting 1 August); the times of the three flights which targeted the plume are also marked on the figure. Following that, the plume only reached Crete once more around day 245 (2 September), after the flight campaign was over, and at a level $(150 \mathrm{hPa})$ which would have been at the ceiling of the DLR Falcon. This emphasizes the important role the chemical weather forecasts had in the successful deployment of the Falcon to observe the plume during the first week of the campaign, prior to the flights focusing primarily on other objectives.

\subsection{The North American plume during CONTRACE}

Based on a recent analysis of the transport of pollutants from North America to Europe (Stohl, 2001) one of the objectives of CONTRACE was to observe the pollution plumes resulting from lifting in frontal disturbances. Three such plumes were observed during CONTRACE, one over southern Scandinavia and Germany (19 November), one over Germany (22 November), and one over Belgium (27 November). This section focuses on the first plume. The origins of the first and third plumes are discussed in Stohl et al. (2003), and a characterization of the chemical nature of the first two plumes is given by Huntrieser et al. (manuscript in preparation). Here we consider the North American plume from the same perspective as the Asian monsoon plume in the previous section, focusing on the MATCH-MPIC forecasts, the comparison with the observations, and the frequency of such plumes.

The North American plume observed during CONTRACE on 19 November 2001 is depicted in Figs. 11 and 12 in a)

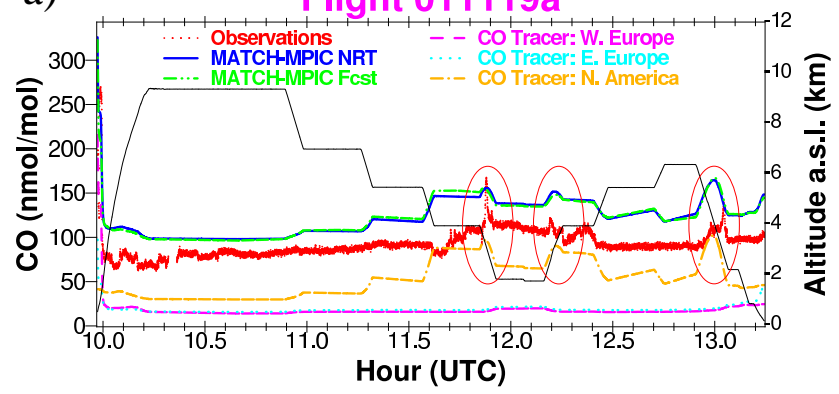

b)

Flight 011119b

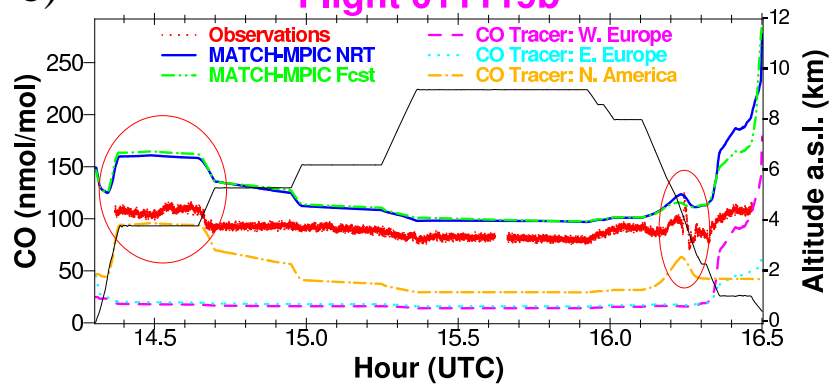

Fig. 15. Comparison of observed and modeled (MATCH-MPIC) $\mathrm{CO}$ mixing ratios $(\mathrm{nmol} / \mathrm{mol})$ and modeled $\mathrm{CO}$ regional tracers along the flight path of the CONTRACE flight on on 19 November 2001, (a) from Oberpfaffenhofen to Stockholm, (b) from Stockholm to Oberpfaffenhofen. The thin black line indicates the altitude, and the ovals indicate the times when the plume was flown through.

terms of the MATCH-MPIC North American CO tracer. The wintertime transatlantic transport of North American pollutants occurs as intermittent air masses lofted by frontal disturbances along the North American east coast, which are then mostly confined to the middle troposphere (MT), between $\sim 500-800 \mathrm{hPa}$. The transport routes vary widely from crossing the Atlantic at $\sim 45^{\circ} \mathrm{N}$ to first entering European air space over northern Greenland and Scandinavia (see the animation of Fig. 12 provided in the supplementary material). The plume observed on 19 November was lifted into the MT between Maine and southern Greenland on 16 and 17 November. An anticyclone over the north Atlantic pulled the original plume apart into two distinct, polluted airmasses, one which remained over Greenland, and another which was rapidly transported at the northern edge of the anticyclone, reaching Norway in the afternoon on the 18th and Germany by the afternoon of the 19th.

The original forecasts figures from MATCH-MPIC and FLEXPART used to plan the flight on 19 November are shown in Fig. 13. Both indicate a clear enhancement in $\mathrm{CO}$ from North America over Scandinavia and northern-central Europe (MATCH-MPIC shows the total CO, which was particularly useful in the flight planning since it indicated that the signal should be easily observable within instrumental uncertainty). The qualitative resemblance between the fore- 

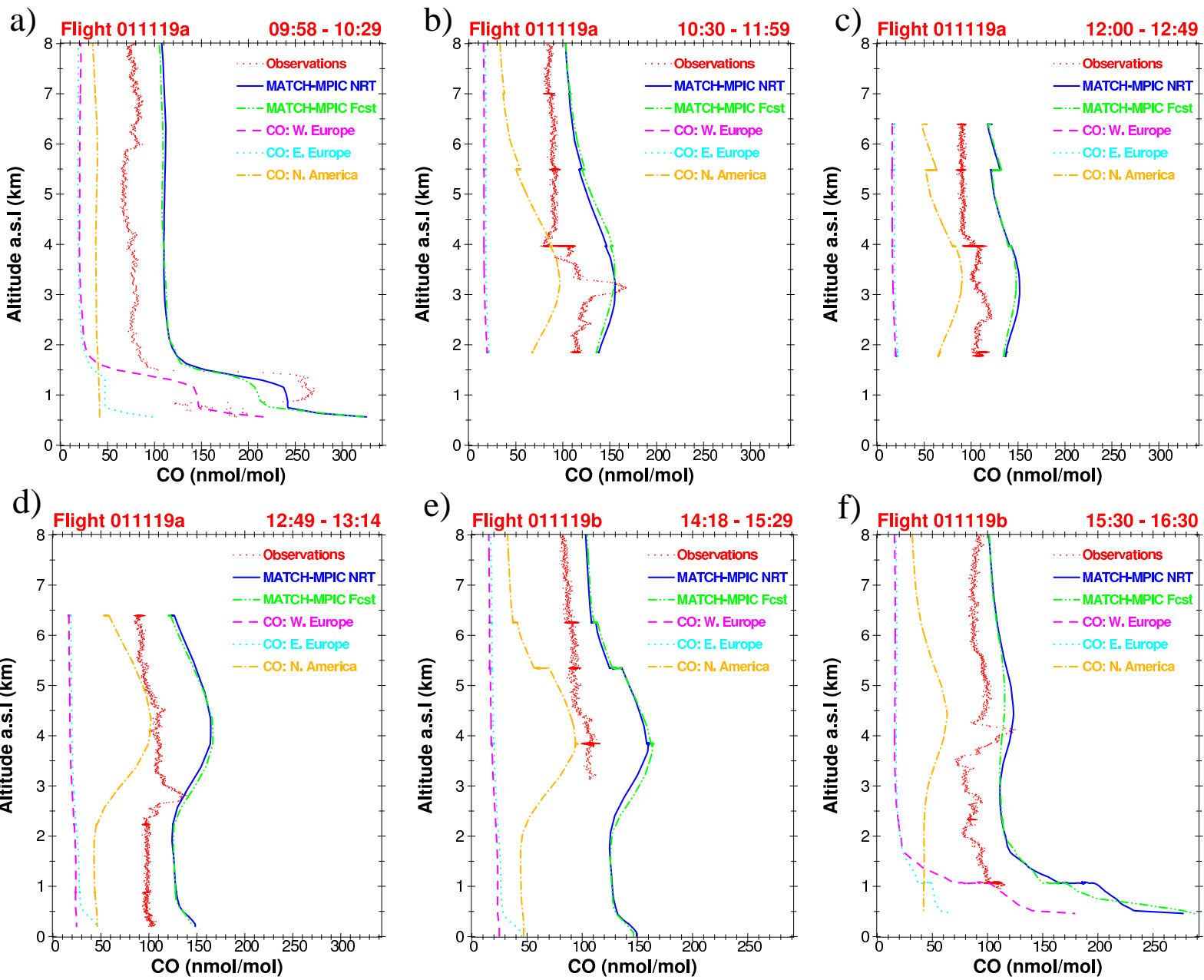

Fig. 16. Vertical profiles of observed CO mixing ratios (nmol/mol), along with the model output (MATCH-MPIC) corresponding to the flight trajectories for the CONTRACE flight from Oberpfaffenhofen to Stockholm on 19 November 2001; the MATCH-MPIC CO is shown for both the near real time (NRT) run and the 2-day forecasts (Fcst), and also includes the regional CO tracers (NRT run) for Western Europe, Eastern Europe and North America. The time range during which each profile was observed is given above each panel. The profiles are located: (a) near Munich (ascent), (b) over Denmark (descent), (c) over Norway (ascent), (d) near Stockholm (descent), (e) near Stockholm (ascent), and (f) near Munich (descent).

casts at $500 \mathrm{hPa}$, despite the widely differing model formulations, provided a considerable degree of confidence for the flight planning. The MATCH-MPIC CO tracers indicated that about half the $\mathrm{CO}$ in this layer came from North America, and the FLEXPART standard forecast figures indicated that the North American plume would also be prevalent at $700 \mathrm{hPa}$. Based on these forecasts, a flight across southern Scandinavia (Fig. 14) was planned for 19 November.

The observed CO levels and the MATCH-MPIC CO and CO tracers are shown in Figs. 15 and 16. The North American plume was flown through 5 times during the two flight legs. The observations show a thin layer of clearly enhanced $\mathrm{CO}$ around $2.5-3 \mathrm{~km}$ during the first leg (Fig. 16b-d), and a second, weaker layer near $4 \mathrm{~km}$. The plume was again observed during the return leg (Fig. 16e and f), with the strongest layer at $\sim 4 \mathrm{~km}$ and a weak enhancement at $2.5 \mathrm{~km}$ during the final descent. These very thin layers are in contrast to the Asian monsoon plume, which extended up to several $\mathrm{km}$ in the vertical. MATCH-MPIC (forecasts and NRT run) computed a single layer of North American CO, about $2 \mathrm{~km}$ deep and centered around 3-4 km; the absence of the layer is also correctly predicted in the first profile (Fig. 16a). Further investigation is needed to determine whether the tendency for MATCH-MPIC to smear out the plumes is due to artificial diffusion resulting from the moderate vertical resolution $(\sim 0.6-0.8 \mathrm{~km})$ or whether excessive physical diffusion or other transport errors are the main cause.

It is remarkable that both the observations and the model (NRT run) indicate the presence of a strong plume near $\mathrm{Mu}$ nich in the late afternoon but not in the morning, considering 

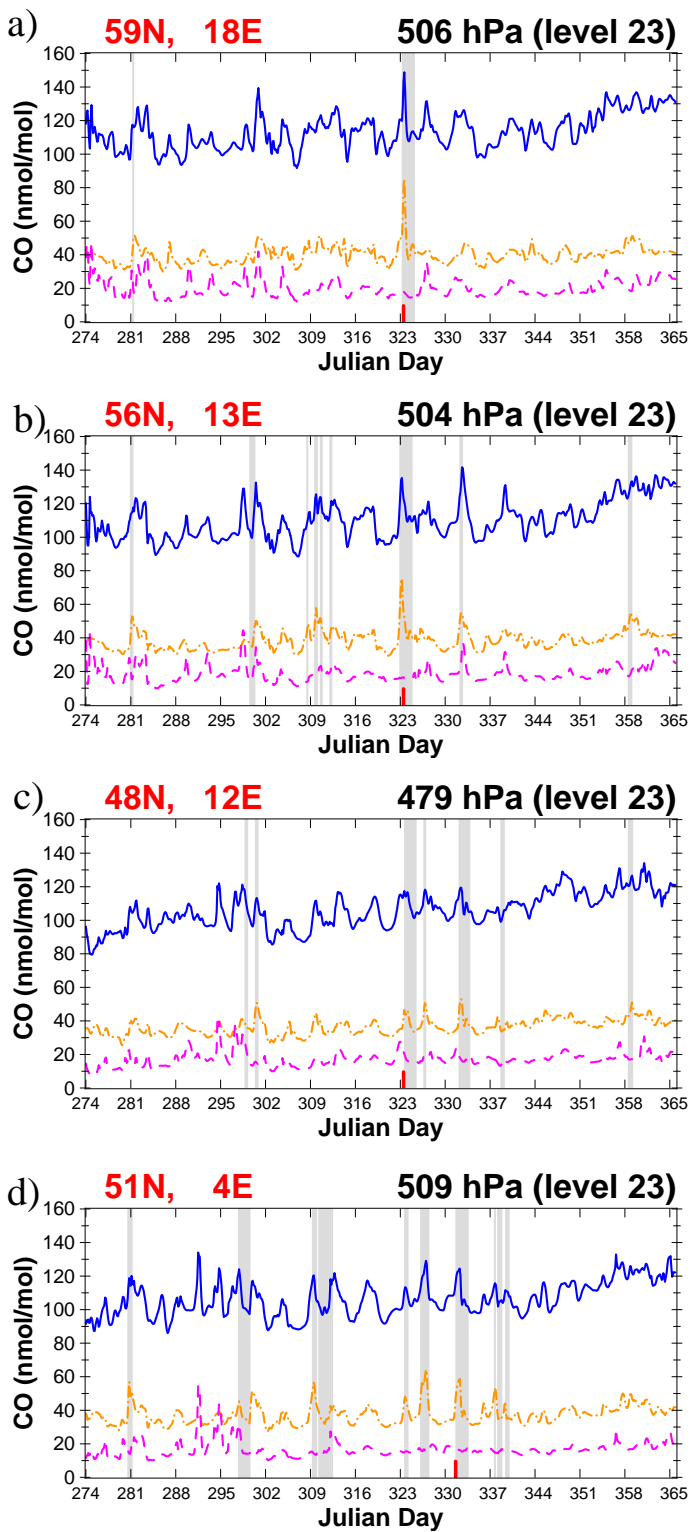

Fig. 17. Mixing ratios (nmol/mol) of $\mathrm{CO}$ (blue, solid line), North American CO (orange, dash-dot line), and Western European CO (magenta, dashed line) from 1 October 2001 (Julian Day 274) to 31 December 2001 (Julian Day 365) at model level $23(\sim 500 \mathrm{hPa})$ over (a) Stockholm, (b) Copenhagen, (c) Munich, and (d) Brussels, based on the MATCH-MPIC NRT run. The flight on 19 November is marked with a red dash on panels (a)-(c), and the flight on 27 November is marked on panel (d). The shaded regions indicate times when a strong plume was present in the column (with $\mathrm{CO}_{t}=25 \mathrm{nmol} / \mathrm{mol}$, see the text for details). The $\mathrm{CO}$ tracers were detrended for spin-up as described in Fig. 10

that the ascending and descending profiles passed through $4 \mathrm{~km}$ altitude within $100 \mathrm{~km}$ (about 1 degree) of each other. According to the MATCH-MPIC results shown earlier in Fig. $12 \mathrm{c}$ and $\mathrm{d}$, this was due to the rapid transport of the plume southwards during the day. At $600 \mathrm{hPa}$, between 09:00
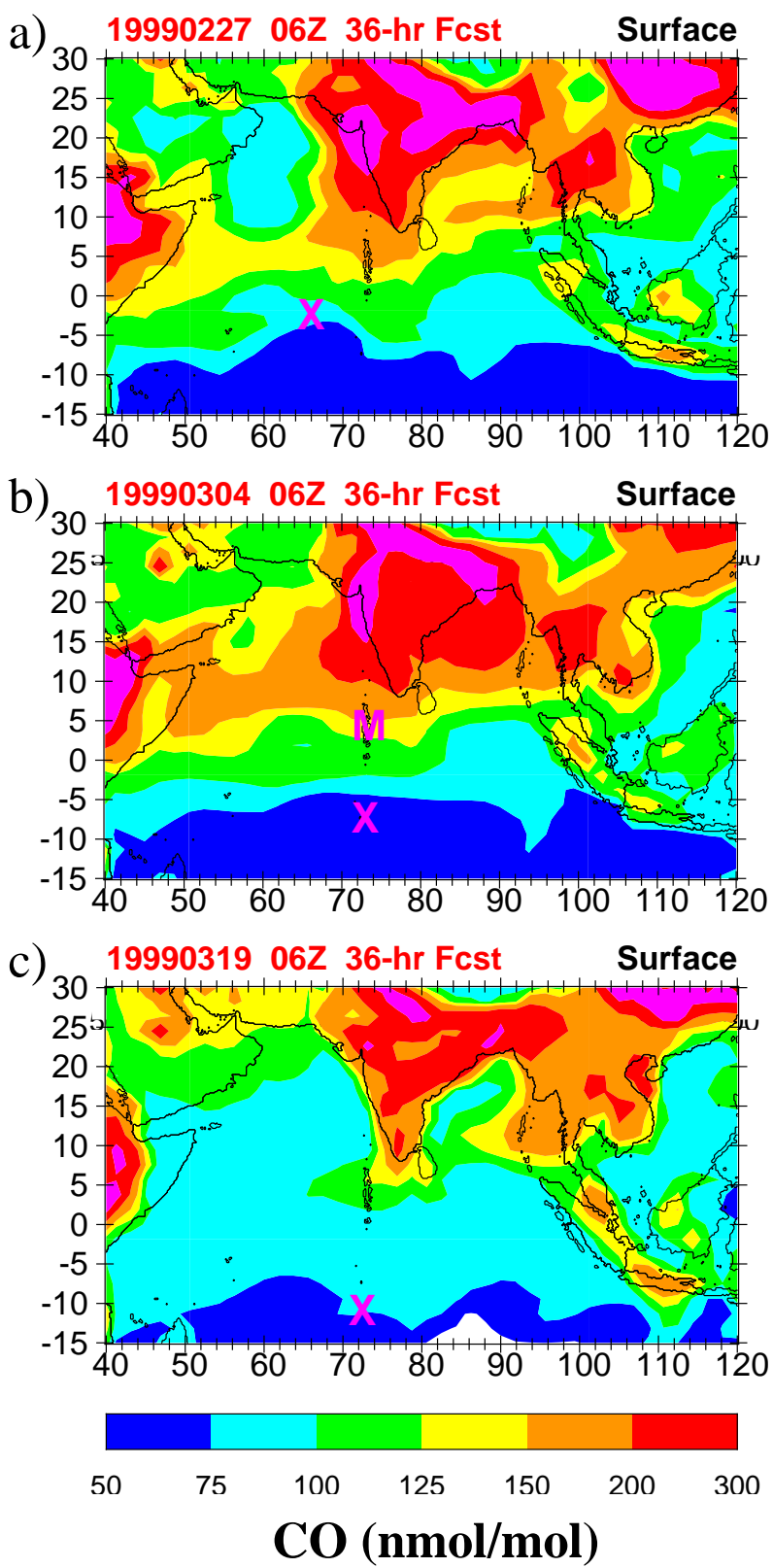

Fig. 18. Surface level distributions of $\mathrm{CO}$ based on the MATCHMPIC 36-hour forecasts for: (a) 27 February (first crossing of the ITCZ by the Ron Brown, marked with "X"), (b) 4 March (southernhemisphere flight with the Citation; southernmost profile is marked with "X", Malé is marked with "M"), and (c) 19 March (second encounter with the ITCZ by the Ron Brown, marked with " $X$ "). The position markings were added post-campaign. The ITCZ is characterized by the transition from typical northern hemispheric values (>80 nmol/mol, light blue) to typical southern hemispheric values $(<70 \mathrm{nmol} / \mathrm{mol}$, dark blue $)$.

and 15:00 UTC the edge of the plume region with significant $\mathrm{CO}$ tracer mixing ratios advances from northern Germany to southern Germany, so that the plume was flown over during 
the steep ascent in the morning, but was intersected during the descent into Oberpfaffenhofen in the afternoon. Notably, the descent into Oberpfaffenhofen was a case in which the forecasts failed to predict the presence of a strong feature only a weak layer was predicted (Fig. 16f) - whereas a strong layer was computed based on the NCEP analysis data (in the NRT run). This is because in the 2-day forecasts the plume lags about $2-3 \mathrm{~h}$ behind the plume in the NRT run, which was sufficient that only a weak $\mathrm{CO}$ enhancement in the layer was computed for the time of the descent ( $\sim 16: 00$ UTC). Nevertheless, the accuracy of the plume arrival time near Munich in this instance - even in the 2-day forecasts, made when the plume was still located over Greenland - indicates that global chemical weather forecasts can be used to predict and allow careful, targeted observations to be made of intercontinental transport phenomena.

In all 5 instances in which a layer with enhanced $\mathrm{CO}$ was observed during a profile on this flight, $\mathrm{O}_{3}$ was also observed to be elevated by $5-10 \mathrm{nmol} / \mathrm{mol}$. However, although MATCH-MPIC computed an enhancement in $\mathrm{CO}$ each time it was observed, the model only computed a very weak enhancement in $\mathrm{O}_{3}$ (a few $\mathrm{nmol} / \mathrm{mol}$ ) in two of these instances, and no enhancement the other three times. This is an indication that the model is underestimating the photochemical $\mathrm{O}_{3}$ production in such pollution plumes, or that the plumes are starting off with too little $\mathrm{O}_{3}$ in the North American BL. In contrast, during the brief encounter with the North American plume over Belgium during the flight on 27 November, no corresponding $\mathrm{O}_{3}$ enhancement was observed. Thus, it is unknown whether these $\mathrm{O}_{3}$ enhancements are normal or an exception during the first flight. However, the potential implications of this are significant: MATCH-MPIC and possibly other similar models may be underestimating the contribution of North American pollution to the $\mathrm{O}_{3}$ burden in the free troposphere over Europe in winter. This issue is being examined in more detail by Huntrieser et al. (manuscript in preparation).

Very strong North American plumes crossing over Stockholm such as the one observed on 19 November are relatively rare. Using the same criterion as defined before to determine the presence of a strong plume in the column (with $\mathrm{CO}_{t}=25 \mathrm{nmol} / \mathrm{mol}$ ), only one other such plume was observed during the period of October-December 2001 (Fig. 17a). Weaker plumes (with $\mathrm{CO}_{t}=20 \mathrm{nmol} / \mathrm{mol}$ ) were more frequent, occurring about $11 \%$ of the time (see Table 4). Pollution lofted directly from western European surface sources also contributes significantly to the variability at this altitude, as depicted by the western European CO tracer in the figure. Further to the south strong North American plume events were more common, though still $<20 \%$ of the time, even for $\mathrm{CO}_{t}=20 \mathrm{nmol} / \mathrm{mol}$. At these low frequencies it would have been difficult to plan flights which could successfully intersect these plumes without the availability of global chemical weather forecasts. a)
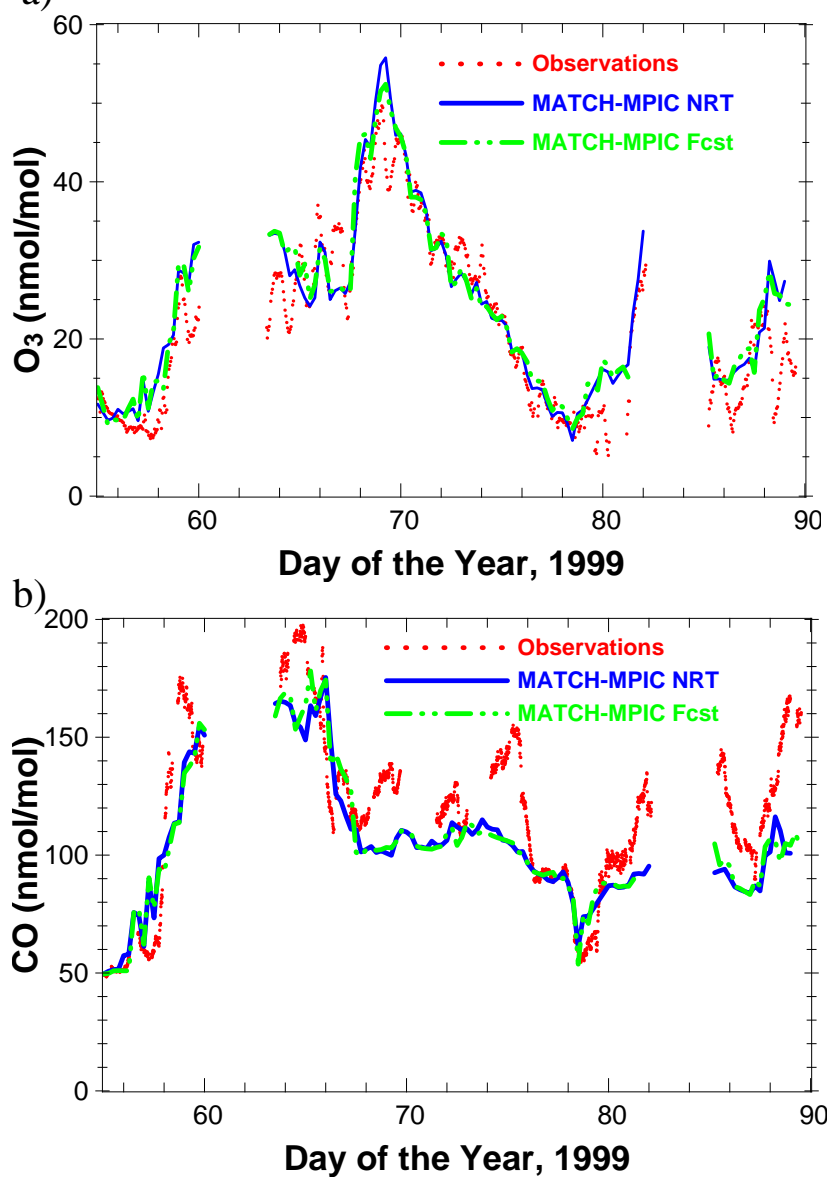

c)

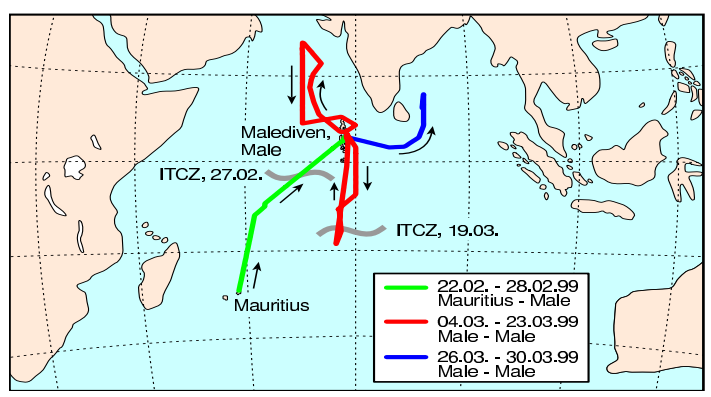

Fig. 19. Comparison of the mixing ratios of (a) $\mathrm{O}_{3}$ and (b) $\mathrm{CO}$ observed during the INDOEX R/V Ronald H. Brown cruise versus the values computed by MATCH-MPIC (near real time run and 2day forecasts). The chemical ITCZ encounters were on Julian day 58 (27 February) and day 78 (19 March). Panel (c) shows the cruise route.

\subsection{The "chemical ITCZ" during INDOEX}

During INDOEX it was found that $\mathrm{O}_{3}$ and $\mathrm{CO}$ have a strong north-south gradient, with very high mixing ratios near the Indian coast (Lal and Lawrence, 2001), being 4-5 times as high as in the pristine southern hemisphere; the sharp transition between these two regimes occurs at the "chemical 
ITCZ". During three separate encounters with the ITCZ (see Fig. 18), MATCH-MPIC was able to predict its variable location (despite the relatively short spin-up time which was possible before INDOEX) and the sharp gradient in trace gas mixing ratios to its north and south.

The chemical ITCZ was encountered twice by the research vessel Ronald H. Brown, once at $2^{\circ} \mathrm{S}$ ( 27 February) and once at $11^{\circ} \mathrm{S}(19 \mathrm{March})$. In both cases the model reproduced the abrupt changes in $\mathrm{CO}$ and $\mathrm{O}_{3}$ well (Fig. 19), and overall the correlation coefficients between the model output and the observations on the Ron Brown were high: $0.91\left(\mathrm{O}_{3}\right)$ and $0.86(\mathrm{CO})$ for the NRT run, and $0.90\left(\mathrm{O}_{3}\right)$ and $0.85(\mathrm{CO})$ for the 2-day forecasts. The second encounter with the Ron Brown was an important application of the MATCH-MPIC forecasts; the ITCZ was barely reached at the farthest extent of a southbound leg, after the chemical weather forecasts alerted the ship crew to the need to travel farther south than originally anticipated, since based on the meteorological forecasts it was expected that the ITCZ would be at about $\sim 6^{\circ} \mathrm{S}$. The difference between this and the location predicted by MATCH-MPIC (about $10-12^{\circ} \mathrm{S}$, Fig $18 \mathrm{c}$ ) may have to do with the nature of the ITCZ here, which slants to the north at higher altitudes (D. R. Sikka, personal communication, 1999). The chemical ITCZ location, based on the surface level CO distribution, could thus be a valuable parameter on which to base future campaign planning decisions for trace gas observations in this region.

During INDOEX, the ITCZ was difficult to reach with the Malé-based Cessna Citation due to its flight range ( $\sim 1000 \mathrm{~km}$ one way), since during much of the campaign the ITCZ was located around $10^{\circ} \mathrm{S}$ at the longitude of Malé $\left(73^{\circ} \mathrm{E}\right)$. The MATCH-MPIC trace gas forecasts were used to predict when the chemical ITCZ would be far enough north for the Citation to reach it, resulting in a multi-leg flight (Flight 11, 4 March 1999) which was successful in sampling southern hemispheric air; very low mixing ratios of $\mathrm{O}_{3}$ $(\sim 10 \mathrm{nmol} / \mathrm{mol})$ and $\mathrm{CO}(\sim 50 \mathrm{nmol} / \mathrm{mol})$ were observed and modeled near the surface in the southernmost profiles. A detailed analysis of the flight is given by Williams et al. (2002).

\section{Conclusions}

Chemical weather forecasts made with MATCH-MPIC have been found to be useful in planning flights targeting different types of synoptic scale phenomena, such as near-surface outflow from nearby polluted regions, intercontinental pollution plumes in the MT and UT, and the separation of the chemical northern and southern hemispheres at the ITCZ. The most valuable gas used during MINOS, CONTRACE, and INDOEX was CO, along with regional CO tracers, due to their relatively well-defined anthropogenic source regions and lifetimes of one to a few months. The modeled CO values were in good agreement with the observations made on nearly all of the flights which were based on the forecasts, with $r>0.7$ and RMS differences (for departures from the respective means) generally within $10-20 \%$ of the observed mean mixing ratios. There is only a slight degradation in the correlations and RMS differences for the 2-day forecasts compared to the NRT run. This ability to reproduce spatial and temporal variations is critical for flight planning. Furthermore, the modeled mean CO levels were within 25-30\% of the observed means, which is within the range of uncertainty in current emissions inventories for emissions from regions such as Asia (e.g. Kasibhatla et al., 2002). Note that due to the high correlations, it seems likely that much of the offsets during INDOEX and CONTRACE can be explained with errors in the emissions datasets, since trace gas concentrations are linear with respect to the production, and errors in the emissions would not be expected to strongly affect the correlations. Errors in the loss or transport terms, on the other hand, will have nonlinear effects on the concentrations, and thus will tend to deteriorate correlations. However, it cannot be ruled out that other model deficiencies contribute, such as errors in the transport (e.g. convection) or loss rates (e.g. $\mathrm{OH})$. The main limitation found was in terms of small-scale features, which can be better represented with regional models. Based on this assessment, we recommend that global and regional (or, where possible, coupled) chemical weather forecasts generally be included as a central component in the daily flight planning of atmospheric chemistry field campaigns.

A major advantage of global (versus regional) chemical weather forecasts is the ability to predict intercontinental transport. A detailed analysis was given of the forecasts and observations of pollution transport from Asia and North America over Europe. Both the Asian monsoon plume and the North American outflow are recurrent features influencing the chemical composition of the MT and UT over Europe. However, the outflow events are intermittent, with the pollution plumes arriving at different geographical locations and altitudes. The Asian monsoon plume was normally limited to being strong only in the eastern Mediterranean, but its altitude varied from covering much of the region above $400 \mathrm{hPa}$, to being confined to only around $150 \mathrm{hPa}$. During the 3-month period around MINOS, a strong plume was present above Crete about $25 \%$ of the time; the only good opportunity to observe the plume was during the first week of MINOS, when three flights were conducted which encountered the anticipated polluted airmasses. The North American plume during CONTRACE was much more intermittent, with strong plumes being present only a small fraction of the time. The North American outflow is generally confined to the MT (between $\sim 500-800 \mathrm{hPa}$ ), and is much more common over west-central Europe (Belgium and Germany) than over Scandinavia. In both campaigns, the chemical weather forecasts were crucial to enabling the plumes to be observed.

It is important to note that synoptic scale $\mathrm{CO}$ distributions can be forecasted accurately (see Table 3) without assimilation of $\mathrm{CO}$ observations. This is in contrast to meteorolog- 
ical weather models, which rapidly diverge from real meteorological conditions if key parameters such as temperature, winds and water vapor are not regularly assimilated. The difference is because the distribution and variability of $\mathrm{CO}$ depends more strongly on the time-dependent boundary values and simulated transport than on the initial conditions, provided that the model has had a sufficient "spin-up" time (order of the trace gas lifetime, a few months in the case of $\mathrm{CO}$ ). For example, the fluctuations in $\mathrm{CO}$ at a remote location depend largely on whether the winds are coming from nearby polluted regions or instead from the "clean sectors," rather than the exact $\mathrm{CO}$ mixing ratios and their histories in each of these regions. Nevertheless, assimilation of CO observations from satellites might help to compensate for errors in the emissions databases or model physics, and provide even more accurate $\mathrm{CO}$ forecasts in the near future, while ongoing model development leads to better $\mathrm{CO}$ forecasts in the long term.

Future developments in chemical weather forecasts will particularly need to focus on going beyond $\mathrm{CO}$ and regional $\mathrm{CO}$ tracers. We have made use of the $\mathrm{O}_{3}$ forecasts in only a few cases so far, and other gases have mostly given a "second opinion" confirming the CO forecasts. Shorterlived tracers will be a particular challenge for the future of chemical weather forecasting. This reflects the general need for further development of global chemistry-transport models. One particular issue which is closely tied to improved chemical weather forecasts is the quality of boundary conditions (emissions and stratospheric influx) used in the models. Currently anthropogenic emissions datasets are about a decade behind the present (1990 in the EDGAR database used for these forecast runs, 1995 in the most recent release), and most models tend to use climatological biogenic sources; normally both are only available on a monthly or annual average basis. Diurnal cycles, weekly traffic cycles, and the stochastic nature of forest fires and lightning $\mathrm{NO}_{x}$ are only a few of the major challenges. One approach to improving these is assimilating relevant observations, such as satellite fire pixel counts for computing surface emissions from biomass burning (e.g. Schultz, 2002), and stratospheric $\mathrm{O}_{3}$ amounts for providing more accurate stratosphere-troposphere fluxes (e.g. Eskes et al., 2002). Other important developments are needed in the chemisty and physics algorithms, such as the transport of soluble gases in hydrometeors, which is very sensitive to several assumptions which are currently highly uncertain, e.g. retention of gases in ice (e.g. Lawrence and Crutzen, 1998; Crutzen and Lawrence, 2000). These basic developments will likely be more important than assimilation of trace gas observations, which are limited by data availability; balloon soundings of $\mathrm{O}_{3}$ (Logan, 1999) are too rare ( $\sim 1 /$ week), too sparse $(<50$ globally), and generally require too long for data delivery to be of use, and while new satellite instruments such as SCIAMACHY are promising, it will still be many years before the vertical resolution for trace gases such as $\mathrm{O}_{3}$ and $\mathrm{NO}_{2}$ im- proves beyond a couple of layers for the entire troposphere.

In parallel to model development, evaluations of the chemical weather simulated by different models are also a critical future need. Until recently, model evaluations largely focused on the chemical climate. In addition to considering field campaign data, long-term datasets with high temporal resolution will be important for assessing chemical weather forecasts. For instance, with respect to the intercontinental plume transport observed during CONTRACE, a possibility to determine the general degree of accuracy of predictions of the North American outflow would be the use of long-term datasets at free tropospheric monitoring stations in the European mountains.

Finally, the applications of global chemical weather forecast systems beyond field measurement campaign planning will need to be explored. One example is more accurate public warnings of summer smog events, and possibly targeted reductions in emissions prior to and during these events. Given the increasing contributions to regional pollution from intercontinental transport (e.g. Jaffe et al., 1999; Berntsen et al., 1999; Jacob et al., 1999; Yienger et al., 2000), boundary conditions from global systems will be crucial in improving the accuracy of regional forecasts for this purpose. Furthermore, there are significant potential agricultural applications. For instance, it has recently been documented (Fumagalli et al., 2001) that the susceptibility of some plants to $\mathrm{O}_{3}$ and other gases is reduced when they are under water stress (due to stomatal closure). It is thus possible that crop damage could be mitigated by carefully controlled irrigation practices based on more accurate future chemical weather forecasts.

Acknowledgements. Thanks to all those who have made MINOS, CONTRACE, and INDOEX possible. Thanks especially to Patrick Jöckel for helping keep the system running during the first 2 weeks of MINOS, and to Jörg Steinkamp for the development of the new interactive web interface and help with $3-\mathrm{D}$ visualizations of the output. Technical assistance from H.-U. Pan with the NCEP data preparation and from Bill Collins, Brian Eaton, Dani Bundy, Steve Williams, Hans-Stefan Bauer and Johann Feichter was appreciated. We are very appreciative of the thorough review by Larry Horowitz. Valuable comments were also provided by T. Kunhikrishnan, Bert Scheeren, and an anonymous referee. This work was supported by funding from the German Ministry of Education and Research (BMBF), project 07-ATC-02.

\section{Appendix: Model Descriptions}

The meteorology component of MATCH simulates advective transport (Rasch and Lawrence, 1998), convection (Zhang and McFarlane, 1995; Hack et al., 1994), vertical diffusion (Holtslag and Boville, 1993), cloud fractions (Slingo, 1987), and cloud microphysics (Rasch and Kristjánsson, 1998). Gridded values for basic meteorological parameters (pressure, temperature, horizontal winds, surface heat fluxes, and surface stresses) are obtained from the National Centers for Environmental Prediction (NCEP) global forecast/analysis 
system (GFS) (Caplan and Pan, 2000). The forecast system employs 3-hourly data from NCEP. Since NCEP only archives its analysis data every $6 \mathrm{~h}$, the data used for the NRT run actually consist of a combination of analysis and forecast data from NCEP, with 0 UTC being analysis, 03:00 UTC the 3-h forecast from 00:00 UTC, 06:00 UTC again being analysis, 09:00 UTC the 3-h forecast from 06:00 UTC, etc. Typically the forecast runs for each day start around 22:00 UTC (after the daily data is processed and transferred). At present the 18:00 UTC data are replaced with the 6-h forecast from 12:00 UTC and the 21:00 UTC data with the 9-h forecast from 12:00 UTC, which allows the NRT run plus the 2.5-day forecast to run overnight.

The remaining meteorological properties (e.g. convective cloud transport) are diagnosed online within MATCH; in particular, the temperature and humidity fields are "destabalized" by advecting them over a timestep before using them to diagnose the moist convection and vertical diffusion (for further details about this procedure the reader is referred to the previous MATCH papers cited in the main text). MATCH has a full tropospheric hydrological cycle; the surface source of water vapor is computed from the latent heat flux in the NCEP data, and the moisture transport and precipitation are computed using the algorithms in MATCH. This gives a water vapor distribution which is internally consistent with the model's meteorology (Rasch et al., 1997; Lawrence et al., 1999).

The tropospheric chemistry module includes isoprene chemistry based on the Mainz Isoprene Mechanism (Pöschl et al., 2000), as well as representations of ethane, propane, ethene, propene, and n-butane (von Kuhlmann et al., 2003). Surface sources of $\mathrm{NO}_{x}, \mathrm{CO}$, and non-methane hydrocarbons (NMHCs) are based on the EDGAR inventory for industrial emissions (Olivier et al., 1999); biomass burning emissions are from Galanter et al. (2000) and Andreae and Merlet (2001), and soil emissions are from Yienger and Levy (1995). The lightning $\mathrm{NO}_{x}$ source distribution is based on the parameterization of Price and Rind (1992, 1994), and aircraft emissions are from Baughcum et al. (1994). The stratospheric influxes of $\mathrm{O}_{3}$ and $\mathrm{NO}_{y}$ are computed by the model's advection scheme, with prescribed stratospheric $\mathrm{O}_{3}$ levels from HALOE satellite measurements (Russel, 1993, and C. Brühl and J.-U. Grooss, personal communication, 1997) and $\mathrm{NO}_{y} / \mathrm{O}_{3}$ ratios based on Murphy et al. (1993). The stratospheric $\mathrm{O}_{3}$ influx has been reduced considerably since the very high amounts in earlier versions of the model; this is done by reducing the prescribed stratospheric $\mathrm{O}_{3}$ mixing ratios each timestep immediately prior to the advection operator and resetting $\mathrm{O}_{3}$ to the HALOE-based values immediately afterwards (see von Kuhlmann, 2001, available at http://www.mpch-mainz.mpg.de/ kuhlmann/rvkdisshtml/ index.html, for further details). Reaction rates are from DeMore et al. (1997), Atkinson et al. (1999), and Sander et al. (2000), and photolysis rates are computed using the technique of Landgraf and Crutzen (1998), including consider- ation of modeled cloud and $\mathrm{O}_{3}$ profiles. Dry deposition is from Ganzeveld and Lelieveld (1995), and heterogeneous loss of $\mathrm{N}_{2} \mathrm{O}_{5}$ on aerosols is based on Dentener and Crutzen (1993). Cloud scavenging by precipitation and gravitational settling processes in non-precipitating clouds are computed based on the modeled precipitation production rates in each grid cell, as described in Lawrence and Crutzen (1998) and Crutzen and Lawrence (2000).

Detailed descriptions of the model and extensive comparisons of the chemical climate versus observations are given in Lawrence et al. (1999), von Kuhlmann (2001), and von Kuhlmann et al. (2003), and are also available via http: //www.mpch-mainz.mpg.de/ lawrence. Like most contemporary models, MATCH-MPIC reproduces most of the major observed features, such as land-sea gradients and vertical profile structures in the tropics and extratropics, particularly for key gases such as $\mathrm{O}_{3}, \mathrm{CO}$, and $\mathrm{NO}_{x}$. However, it also has a number of unexplained discrepancies with the observations which are common in contemporary models, such as the $\mathrm{NO}_{x} / \mathrm{HNO}_{3}$ ratio (Thakur et al., 1999).

Brief descriptions of ECHAM, FLEXPART, and EURAD are:

1. The forecast runs with ECHAM5 (successor to ECHAM4, Roeckner et al., 1996, 1999) were nudged with ECMWF winds, using a horizontal resolution of T42 $(2.8 \times 2.8 \mathrm{deg})$ and 19 vertical levels. $\mathrm{CO}$ was divided into 14 tracers for different regions and emissions sources. The emissions for ECHAM were from the MOZART 2 model (Horowitz et al., 2003), and $\mathrm{OH}$ is prescribed as monthly mean fields from Spivakovsky et al. (2000). Details are available via http: //www.mpimet.mpg.de/en/depts/bgcs/ac/.

2. FLEXPART (Stohl et al., 1998) is a Lagrangian particle dispersion model. It uses the EDGAR industrial CO emissions inventory for the year 1990 (the same as used in MATCH-MPIC); other sources (biogenic and NMHC oxidation) are not included. No decay of $\mathrm{CO}$ is assumed, and the tracer particles are carried in the simulation until they are 20 days old. About 70000 particles were emitted per day, so that about 1.4 million particles were present at any time in the simulations. The input emissions and meteorology are on a $1 \times 1$ degree grid, and the output is also at the same resolution (with $1000 \mathrm{~m}$ vertical resolution). Forecasts are updated every $6 \mathrm{~h}$. Details are available via http://www.forst.uni-muenchen.de/EXT/LST/ METEO/stohl/flexpart.html.

3. EURAD (Jakobs et al., 1995; Memmesheimer et al., 1995) is a regional chemistry-transport model centered over Europe which contains the complex RADM2 chemical integration scheme (Stockwell et al., 1990) coupled with aerosol chemistry (Ackermann et al., 1998; Schell et al., 2001) and with a detailed emissions 
database for Europe, and uses the meteorology from forecasts with the MM5 mesoscale model, initialized with NCEP AVN wind fields, to drive the transport of trace gases. Details are available via http://www.eurad. uni-koeln.de/index_e.html.

\section{References}

Ackermann, I., Hass, H., Memmesheimer, M., Ebel, A., Binkowski, F., and Shankar, U.: Modal aerosol dynamics model for Europe: Development and first applications, Atmos. Environ., 32, 28912999, 1998.

Andreae, M. O. and Merlet, P.: Emission of trace gases and aerosols from biomass burning, Global Biogeochem. Cycles, 15, 955966, 2001

Atkinson, R., Baulch, D. L., Cox, R. A., Hampson, Jr, R. F., Kerr, J. A., Rossi, M. J., and Troe, J.: Evaluated kinetic and photochemical data for atmospheric chemistry, organic species: Supplement vii, J. Phys. Chem. Ref. Data, 28, 191-393, http: //www.iupac-kinetic.ch.cam.ac.uk/, 1999.

Baughcum, S. L., Henderson, S. C., Hertel, P. S., Maggiora, D. R., and Oncina, C. A.: Stratospheric emissions effects database developement, Contr. rep. cr-4592, NASA, 1994.

Benoit, R., Schär, C., Binder, P., Chamberland, S., Davies, H. C., Desgagne, M., Girard, C., Keil, C., adn D. Lüthi, N. K., Müller, E., Pellerin, P., Schmidli, J., Schubiger, F., Schwierz, C., Sprenger, M., Walser, A., Willemse, S., Yu, W., and Zala, E.: The real-time ultrafinescale forecast support during the special observing period of the MAP, Bull. Am. Met. Soc., 83, 85-109. 2002.

Berntsen, T. K., Karlsdòttir, S., and Jaffe, D. A.: Influence of Asian emissions on the composition of air reaching the North Western United States, Geophys. Res. Lett., 26, 2171-2174, 1999.

Caplan, P. and Pan, H.-L.: Changes to the 1999 NCEP Operational MRF Model Analysis/Forecast System, NCEP Pub. No. 452, National Centers for Environmental Prediction, Silver Spring, 2000.

Collins, W. D., Rasch, P. J., Eaton, B. E., Khattatov, B. V., Lamarque, J., and Zender, C. S.: Simulating aerosols using a chemical transport model with assimilation of satellite aerosol retrievals: Methodology for INDOEX, J. Geophys. Res., 106, 7313-7336, 2001.

Crutzen, P. J. and Lawrence, M. G.: The impact of precipitation scavenging on the transport of trace gases: A 3-dimensional model sensitivity study, J. Atmos. Chem., 37, 81-112, 2000.

Crutzen, P. J. and Ramanathan, V.: Forward to the Indian Ocean Experiment special section, part 1, J. Geophys. Res., 106, 28369 $28370,2001$.

Das, P. K.: The Monsoons, National Book Trust, India, New Delhi, 1992.

de Gouw, J. A., Warneke, C., Scheeren, H. A., van der Veen, C., Bolder, M., Scheele, M. P., Williams, J., Wong, S., Lange, L., Fischer, H., and Lelieveld, J.: Overview of the trace gas measurements on board the Citation aircraft during the intensive field phase of INDOEX, J. Geophys. Res., 106, 28 453-28 467, 2001. DeMore, W. B., Sander, S. P., Howard, C. J., Ravishankara, A. R., Golden, D. M., Kolb, C. E., Hampson, R. F., Kurylo, M. J., and Molina, M. J.: Chemical kinetics and photochemical data for use in stratospheric modeling, Evaluation 12, 97-4, Jet Propulsion Laboratory, Pasadena, California, 1997.

Dentener, F. J. and Crutzen, P. J.: Reaction of $\mathrm{N}_{2} \mathrm{O}_{5}$ on tropospheric aerosols: Impact on the global distributions of $\mathrm{NO}_{x}, \mathrm{O}_{3}$, and $\mathrm{OH}$ J. Geophys. Res., 98, 7149-7163, 1993.

Dickerson, R. R. and Delany, A. C.: Modification of a commercial gas filter correlation $\mathrm{CO}$ detector for enhanced sensitivity, $\mathrm{J}$. Atmos. Oceanic Tech., 5, 424-431, 1998.

Emmons, L. K., Carroll, M. A., Hauglustaine, D. A., Brasseur, G. P., Atherton, C., Penner, J., Sillman, S., Levy II, H., Rohrer, F., Wauben, W. M. F., Velthoven, P. F. J. V., Wang, Y., Jacob, D., Bakwin, P., Dickerson, R., Doddridge, B., Gerbig, C., Honrath, R., Hübler, G., Jaffe, D., Kondo, Y., Munger, J. W., Torres, A., and Volz-Thomas, A.: Climatologies of $\mathrm{NO}_{x}$ and $\mathrm{NO}_{y}$ : A comparison of data and models, Atmos. Environ., 31, 1851-1904, 1997.

Eskes, H. J., van Velthoven, P. F. J., and Kelder, H. M.: Global ozone forecasting based on ERS-2 GOME observations, Atmos. Chem. Phys. Discuss., 2, 921-942, 2002.

Flatoy, F., Hov, O., and Schlager, H.: Chemical forecasts used for measurement flight planning during POLINAT 2, Geophys. Res. Lett., 27, 951-954, 2000.

Fumagalli, I., Gimeno, B. S., Velissariou, D., Temmerman, L. D., and Mills, G.: Evidence of ozone-induced adverse effects on crops in the mediterranean region, Atmos. Environ., 35, 2583 2587, 2001.

Galanter, M., Levy, H. and Carmichael, G. R.: Impacts of biomass burning on tropospheric $\mathrm{CO}, \mathrm{NO}_{x}$, and $\mathrm{O}_{3}$, J. Geophys. Res., 105, 6633-6653, 2000.

Ganzeveld, L. and Lelieveld, J.: Dry deposition parameterization in a chemistry general circulation model and its influence on the distribution of reactive trace gases, J. Geophys. Res., 100, 20 999-21 012, 1995.

Gerbig, C., Schmitgen, S., Kley, D., Volz-Thomas, A., Dewey, K., and Haaks, D.: An improved fast-response vacuum-uv resonance fluorescence co instrument, J. Geophys. Res., 104, 1699-1704, 1999.

Hack, J. J., Boville, B. A., Kiehl, J. T., Rasch, P. J., and Williamson, D. L.: Climate statistics from the National Center for Atmospheric Research community climate model CCM2, J. Geophys. Res., 99, 20 785-20813, 1994.

Hauglustaine, D. A., Brasseur, G. P., Walters, S., Rasch, P. J., Müller, J.-F., Emmons, L. K., and Carroll, M. A.: MOZART, a global chemical transport model for ozone and related chemical tracers, 2: model results and evaluation, J. Geophys. Res., 103, 28 291-28 335, 1998.

Holtslag, A. A. M. and Boville, B. A.: Local versus nonlocal boundary-layer diffusion in a global climate model, J. Climate, 6, 1825-1842, 1993.

Horowitz, L. W., Walters, S., Mauzerall, D. L., Emmons, L. K., Rasch, P. J., Granier, C., Tie, X., Lamarque, J.-F., Schultz, M. G., Tyndall, G. S. Orlando, J. J., and Brasseur, G. P.: A global simulation of tropospheric ozone and related tracers: Description and evaluation of MOZART, version 2, submitted to J. Geophys. Res., 2003.

Jacob, D. J., Logan, J. A., and Murti, P. P.: Effect of rising Asian emissions on surface ozone in the United States, Geophys. Res. Lett., 26, 2175-2178, 1999.

Jaffe, D., Anderson, T., Covert, D., Kotchenruther, R., Trost, B., 
Danielson, J., Simpson, W., Berntsen, T., Karlsdottir, S., Blake, D., Harris, J., Carmichael, G., and Uno, I.: Transport of Asian air pollution to North America, Geophys. Res. Lett., 26, 711714, 1999.

Jakobs, H. J., Feldmann, H., Hass, H., and Memmesheimer, M.: The use of nested models for air pollution studies: An application of the EURAD model to a SANA episode, J. Appl. Met., 34, 1301-1319, 1995.

Kasibhatla, P. Arellano, A., Logan, J. A., Palmer, P. I. and Novelli, P.: Top-down estimate of a large source of atmospheric carbon monoxide associated with fuel combustion in Asia, Geophys. Res. Lett., 29, 10.1029/2002GL015561, 2002.

Lal, S. and Lawrence, M. G.: Elevated mixing ratios of surface ozone over the Arabian Sea, Geophys. Res. Lett., 28, 1487-1490, 2001.

Landgraf, J. and Crutzen, P. J.: An efficient method for online calculations of photolysis and heating rates, J. Atmos. Sci., 55, 863878, 1998.

Lawrence, M. G. and Crutzen, P. J.: The impact of cloud particle gravitational settling on soluble trace gas distributions, Tellus, 50B, 263-289, 1998.

Lawrence, M. G., Crutzen, P. J., Rasch, P. J., Eaton, B. E., and Mahowald, N. M.: A model for studies of tropospheric photochemistry: Description, global distributions, and evaluation, J. Geophys. Res., 104, 26 245-26277, 1999.

Lee, A. M., Carver, G. D., Chipperfield, M. P., and Pyle, J. A.: Three-dimensional chemical forecasting: A methodology, J. Geophys. Res., 102, 3905-3919, 1997.

Lelieveld, J., Berresheim, H., Borrmann, S., Crutzen, P. J., Dentener, F. J., Fischer, H., de Gouw, J., Feichter, J., Flatau, P., Heland, J., Holzinger, R., Korrmann, R., Lawrence, M., Levin, Z., Markowicz, K., Mihalopoulos, N., Minikin, A., Ramanathan, V., de Reus, M., Roelofs, G.-J., Scheeren, H. A., Sciare, J., Schlager, H., Schultz, M., Siegmund, P., Steil, B., Stephanou, E., Stier, P., Traub, M., Williams, J., and Ziereis, H.: Global air pollution crossroads over the Mediterranean, Science, 298, 794-799, 2002.

Logan, J. A.: An analysis of ozonesonde data for the troposphere: Recommendations for testing 3-D models and development of a gridded climatology for tropospheric ozone, J. Geophys. Res., 104, 16 115-16 149, 1999.

Mahowald, N. M., Prinn, R., and Rasch, P. J.: Deducing $\mathrm{CCl}_{3} \mathrm{~F}$ emissions using an inverse method and chemical transport models with assimilated winds, J. Geophys. Res., 102, $28153-$ 28 168, 1997a.

Mahowald, N. M., Rasch, P. J., Eaton, B. E., Whittlestone, S., and Prinn, R. G.: Transport of ${ }^{222}$ radon to the remote troposphere using the Model of Atmospheric Transport and Chemistry and assimilated winds from ECMWF and the National Center for Environmental Prediction/NCAR, J. Geophys. Res., 102, 28 139$28152,1997 \mathrm{~b}$.

Memmesheimer, M., Hass, H., Tippke, J., and Ebel, A.: Modeling of episodic emission data for Europe with the EURAD Emission Model (EEM), 2, 495-499, Air and Waste Manage. Assoc., 1995. Murphy, D. M., Fahey, D. W., Proffitt, M. H., Liu, S. C., Chan, K. R., Eubank, C. S., Kawa, S. R., and Kelly, K. K.: Reactive nitrogen and its correlation with ozone in the lower stratosphere and upper troposphere, J. Geophys. Res., 98, 8751-8773, 1993.

Olivier, J. G. J., Bloos, J. P. J., Berdowski, J. J. M., Visschedijk, A.
J. H., and Bouwman, A. F.: A 1990 global emission inventory of anthropogenic sources of carbon monoxide on $1^{\circ} \times 1^{\circ}$ developed in the framework of EDGAR/GEIA, Chemosphere: Global Change Science, 1, 1-17, 1999.

Pöschl, U., von Kuhlmann, R., Poisson, N., and Crutzen, P. J.: Development and intercomparison of condensed isoprene oxidation mechanisms for global atmospheric modeling, J. Atmos. Chem., 37, 29-52, 2000.

Price, C. and Rind, D.: A simple lightning parameterization for calculating global lightning distributions, J. Geophys. Res., 97, 9919-9933, 1992.

Price, C. and Rind, D.: Modeling global lightning distributions in a general circulation model, Mon. Weather Rev., 122, 1930-1937, 1994.

Rasch, P. J. and Kristjánsson, J. E.: A comparison of the CCM3 model climate using diagnosed and predicted condensate parameterizations, J. Climate, 11, 1587-1614, 1998.

Rasch, P. J. and Lawrence, M. G.: Recent developments in transport methods at NCAR, Tech. Rep. 265, Max-Planck-Institut für Meteorologie, Bundesstrasse 55, 20146 Hamburg, Germany, 1998.

Rasch, P. J., Mahowald, N. M., and Eaton, B. E.: Representations of transport, convection and the hydrologic cycle in chemical transport models: Implications for the modeling of short lived and soluble species, J. Geophys. Res., 102, 28 127-28 138, 1997.

Rasch, P. J., Collins, W. D., and Eaton, B. E.: Understanding the Indian Ocean Experiment (INDOEX) aerosol distributions with an aerosol assimilation, J. Geophys. Res., 106, 7337-7355, 2001.

Roeckner, E., Arpe, K., Bengtsson, L., Christoph, M., Claussen, M., Dümenil, L., Esch, M., Giorgetta, M., Schlese, U., and Schulzweida, U.: The atmospheric general circulation model ECHAM-4: Model description and simulation of present-day climate, Tech. rep., Max-Planck-Institut für Meteorologie, Bundesstrasse 55, 20146 Hamburg, Germany, 1996.

Roeckner, E., Bengtsson, L., Feichter, J., Lelieveld, J., and Rodhe, H.: Transient climate change simulations with a coupled atmosphere-ocean GCM including the tropospheric sulfur cycle, J. Climate, 12, 3004-3032, 1999.

Russel, J.: The halogen occultation experiment, J. Geophys. Res., 98, 10777-10 798, 1993.

Sander, S. P., Friedl, R. R., DeMore, W. B., Ravishankara, A. R., Golden, D. M., Kolb, C. E., Kurylo, M. J., Hampson, R. F., Huie, R. E., Molina, M. J., and Moortgat, G. K.: Chemical kinetics and photochemical data for use in stratospheric modeling - supplement to evaluation 12: Update of key reactions, Evaluation 13, 00-3, Jet Propulsion Laboratory, Pasadena, California, 2000.

Scheeren, B., Lelieveld, J., Roelofs, G.-J., Williams, J., Fischer, H., de Reus, M., de Gouw, J. A., Warneke, C., Holzinger, R., Schlager, H., Klüpfel, T., Bolder, M., van der Veen, C., and Lawrence, M. G.: The impact of monsoon outflow from SouthEast Asia in the upper troposphere over the eastern Mediterranean, Atmos. Chem. Phys., this issue, 2003.

Schell, B., Ackermann, I., Hass, H., Binkowski, F., and Ebel, A.: Modeling the formation of secondary organic aerosol with a comprehensive air quality modeling system, J. Geophys. Res., 106, 28 275-28 293, 2001.

Schlager, H., Konopka, P., Schulte, P., Schumann, U., Ziereis, H., Arnold, F., Klemm, M., Hagen, D., Whitefield, P., and Ovarlez, J.: In situ observations of air traffic emission signatures in the North Atlantic flight corridor, J. Geophys. Res., 102, 10739 
10750, 1997.

Schultz, M. G.: On the use of atsr fire count data to estimate the seasonal and interannual variability of vegetation fire emissions, Atmos. Chem. Phys. Discuss., 2, 1159-1179, 2002.

Slingo, J. M.: The development and verification of a cloud prediction scheme for the ECMWF model, Q. J. R. Meteorol. Soc., 113, 899-927, 1987.

Spivakovsky, C. M., Logan, J. A., Montzka, S. A., Balkanski, Y. J., Foreman-Fowler, M., Jones, D. B. A., Horowitz, L. W., Fusco, A. C., Brenninkmeijer, C. A. M., Prather, M. J., Wofsy, S. C., and McElroy, M. B.: Three-dimensional climatological distribution of tropospheric $\mathrm{OH}$ : Update and evaluation, J. Geophys. Res., 105, 8931-8980, 2000.

Stehr, J. W., Ball, W. P., Dickerson, R. R., Doddridge, B. G., Piety, C. A., and Johnson, J. E.: Latitudinal gradients in $\mathrm{O}_{3}$ and $\mathrm{CO}$ during INDOEX 1999, J. Geophys. Res., in press, 2002.

Stockwell, W. R., Middleton, P., Chang, J. S., and Tang, X.: The second generation regional acid deposition model chemical mechanism for regional air quality modeling, J. Geophys. Res., 95, 16343-16367, 1990.

Stohl, A.: A 1-year lagrangian "climatology" of airsteams in the Northern Hemisphere troposphere and lowermost stratosphere, J. Geophys. Res., 106, 7263-7279, 2001.

Stohl, A., Hittenberger, M., and Wotawa, G.: Validation of the lagrangian particle dispersion model flexpart against large scale tracer experiment data, Atmos. Environ., 24, 4245-4264, 1998.

Stohl, A., Forster, C., Eckhardt, S., Huntrieser, H., Heland, J., Schlager, H., Aufmhoff, H., Arnold, F., and Cooper, O.: An inverse modeling study of intercontinental pollution transport using aircraft measurements, J. Geophys. Res., in press, 2003.
Thakur, A. N., Singh, H. B., Mariani, P., Chen, Y., Wang, Y., Jacob, D. J., Brasseur, G., Müller, J., and Lawrence, M.: Distribution of reactive nitrogen species in the remote free troposphere: data and model comparisons, Atmos. Environ., 33, 1403-1422, 1999.

von Kuhlmann, R., Lawrence, M. G., Crutzen, P. J., and Rasch, P. J.: A Model for Studies of Tropospheric Ozone and Non-Methane Hydrocarbons: Model Description and Ozone Results, J. Geophys. Res., in press, 2002JD002893, 2003.

von Kuhlmann, R.: Photochemistry of Tropospheric Ozone, its Precursors and the Hydroxyl Radical: A 3D-Modeling Study Considering Non-Methane Hydrocarbons, Ph.D. thesis, Johannes Gutenberg-Universität Mainz, Mainz, Germany, 2001.

Wienhold, F., Fischer, H., Hoor, P., Wagner, V., Konigstedt, R., Harris, G., Anders, J., Grisar, R., Knothe, M., Riedel, W., Lubken, F., and Schilling, T.: Tristar - a tracer in situ tdlas for atmospheric research, App. Phys. B-Lasers and Optics, 67, 411-417, 1998.

Williams, J., Fischer, H., Wong, S., Crutzen, P., Scheele, R., and Lelieveld, J.: Near equatorial $\mathrm{CO}$ and $\mathrm{O}_{3}$ profiles over the Indian Ocean during the winter monsoon: $\mathrm{High}_{3}$ levels in the middle troposphere and interhemispheric exchange, J. Geophys. Res., in press, 2002.

Yienger, J., Galanter, M., Holloway, T., Phadnis, M., Guttikunda, S., Carmichael, G., Moxim, W., and Levy, H.: The episodic nature of air pollution transport from Asia to North America, J. Geophys. Res., 105, 26 931-26 945, 2000.

Yienger, J. J. and Levy, H.: Empirical model of global soil-biogenic $\mathrm{NO}_{x}$ emissions, J. Geophys. Res., 100, 11 447-11 464, 1995.

Zhang, G. J. and McFarlane, N. A.: Sensitivity of climate simulations to the parameterization of cumulus convection in the Canadian Climate Centre general circulation model, Atmos. Ocean, 33, 407-446, 1995. 